\title{
TRAINSPOTTING 2012: TRAVEL, LEISURE, AND EVERYDAY LIFE IN HONG KONG
}

By

Robin Lo

A thesis submitted to the Faculty of Graduate and Postdoctoral

Affairs in partial fulfillment of the requirements for the degree of

Master of Architecture

$\ln$

Azrieli School of Architecture and Urbanism

Carleton University

Ottawa, Ontario

(C) 2012

Robin Lo 
Library and Archives

Canada

Published Heritage

Branch

395 Wellington Street

Ottawa ON K1A ON4

Canada
Bibliothèque et

Archives Canada

Direction du

Patrimoine de l'édition

395 , rue Wellington

Ottawa ON K1A ON4

Canada
Your file Votre référence

ISBN: 978-0-494-91522-6

Our file Notre référence

ISBN: $978-0-494-91522-6$
NOTICE:

The author has granted a nonexclusive license allowing Library and Archives Canada to reproduce, publish, archive, preserve, conserve, communicate to the public by telecommunication or on the Internet, loan, distrbute and sell theses worldwide, for commercial or noncommercial purposes, in microform, paper, electronic and/or any other formats.

The author retains copyright ownership and moral rights in this thesis. Neither the thesis nor substantial extracts from it may be printed or otherwise reproduced without the author's permission.
AVIS:

L'auteur a accordé une licence non exclusive permettant à la Bibliothèque et Archives Canada de reproduire, publier, archiver, sauvegarder, conserver, transmettre au public par télécommunication ou par l'Internet, prêter, distribuer et vendre des thèses partout dans le monde, à des fins commerciales ou autres, sur support microforme, papier, électronique et/ou autres formats.

L'auteur conserve la propriété du droit d'auteur et des droits moraux qui protege cette thèse. $\mathrm{Ni}$ la thèse ni des extraits substantiels de celle-ci ne doivent être imprimés ou autrement reproduits sans son autorisation.
In compliance with the Canadian Privacy Act some supporting forms may have been removed from this thesis.

While these forms may be included in the document page count, their removal does not represent any loss of content from the thesis.
Conformément à la loi canadienne sur la protection de la vie privée, quelques formulaires secondaires ont été enlevés de cette thèse.

Bien que ces formulaires aient inclus dans la pagination, il n'y aura aucun contenu manquant. 


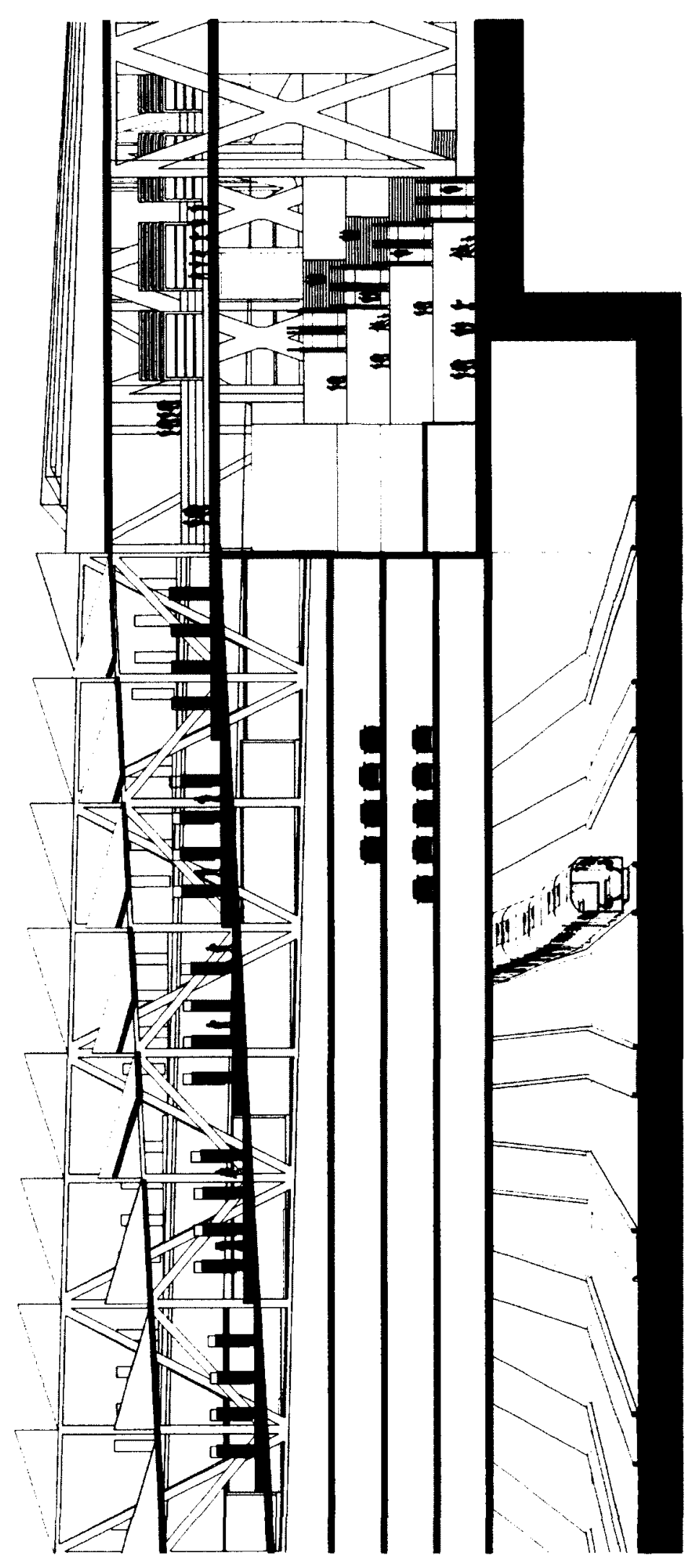


in the early 1800s. While constant technological and material advancements have drastically altered the appearance of the terminal, the basic components have remained relatively constant. Even recent, seemingly complex stations can be distilled down to the basic components of arrival/departure platforms, ticketing halls and train sheds. While many modern intermodal transport hubs have capitalized on the commercial opportunities from the vast passenger flow in stations by incorporating programs such as hotels and shopping malls into the design, the inherent temporality of the station typology remains. Modern cities require increasing numbers of inter-city rail terminals to be built near their cores in order to connect with local transportation networks. If the train station is becoming more integrated into the urban city core, it should evolve from a transitory interchange into a more permanent urban institution. This project advances a new railway station as an urban hub for Hong Kong Organized as a block-wide complex, it offers a new horizontal datum to counter the "podium and tower" typical of the city's development. The station is host to a series of large-scale programs aimed at enriching the everyday life of Kowloon West. 


\section{Acknowledgement}

I would like to express my deep gratitude and appreciation to my thesis advisor, Professor Inderbir Riar. His valuable input, coupled with his firm commitment to my thesis was the primary driving force for my research in the past year. I would also like to thank my friends and colleagues who provided constant encouragement and support throughout the thesis process. 


\section{Table of Contents}

\section{Acknowledgement}

Introduction

The Railway Station $\quad 8$

1.1 The Emergence of the Railway Type …......................................................................... 9

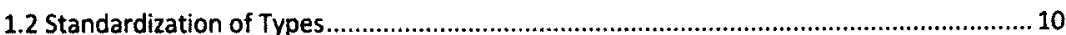

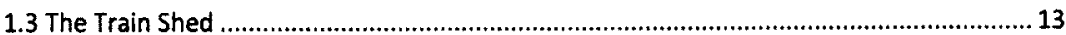

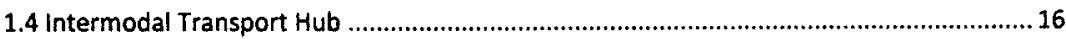

1.4.1 Intermodal Transport Hubs in Hong Kong ......................................................... 19

2.0 Hong Kong : A Culture of Transition 20

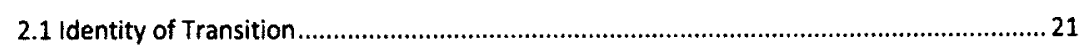

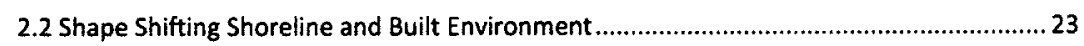

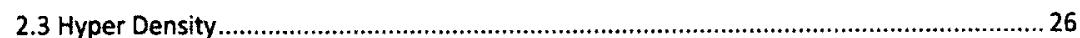

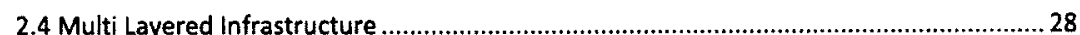

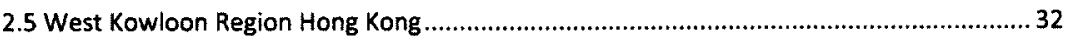

3.0 Project35

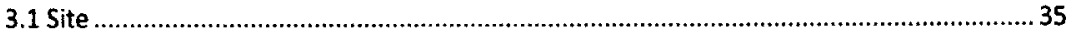

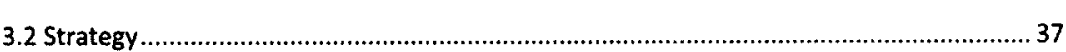

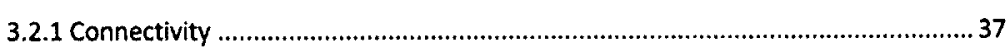

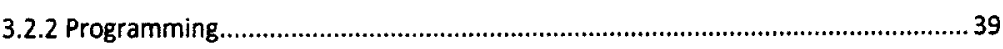

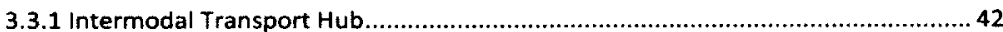

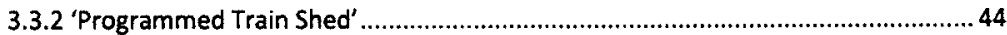

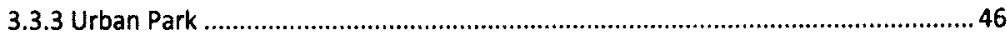

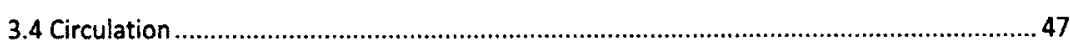

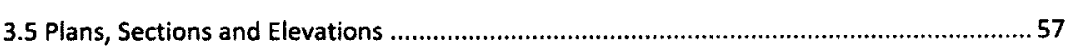




\section{List of Illustrations}

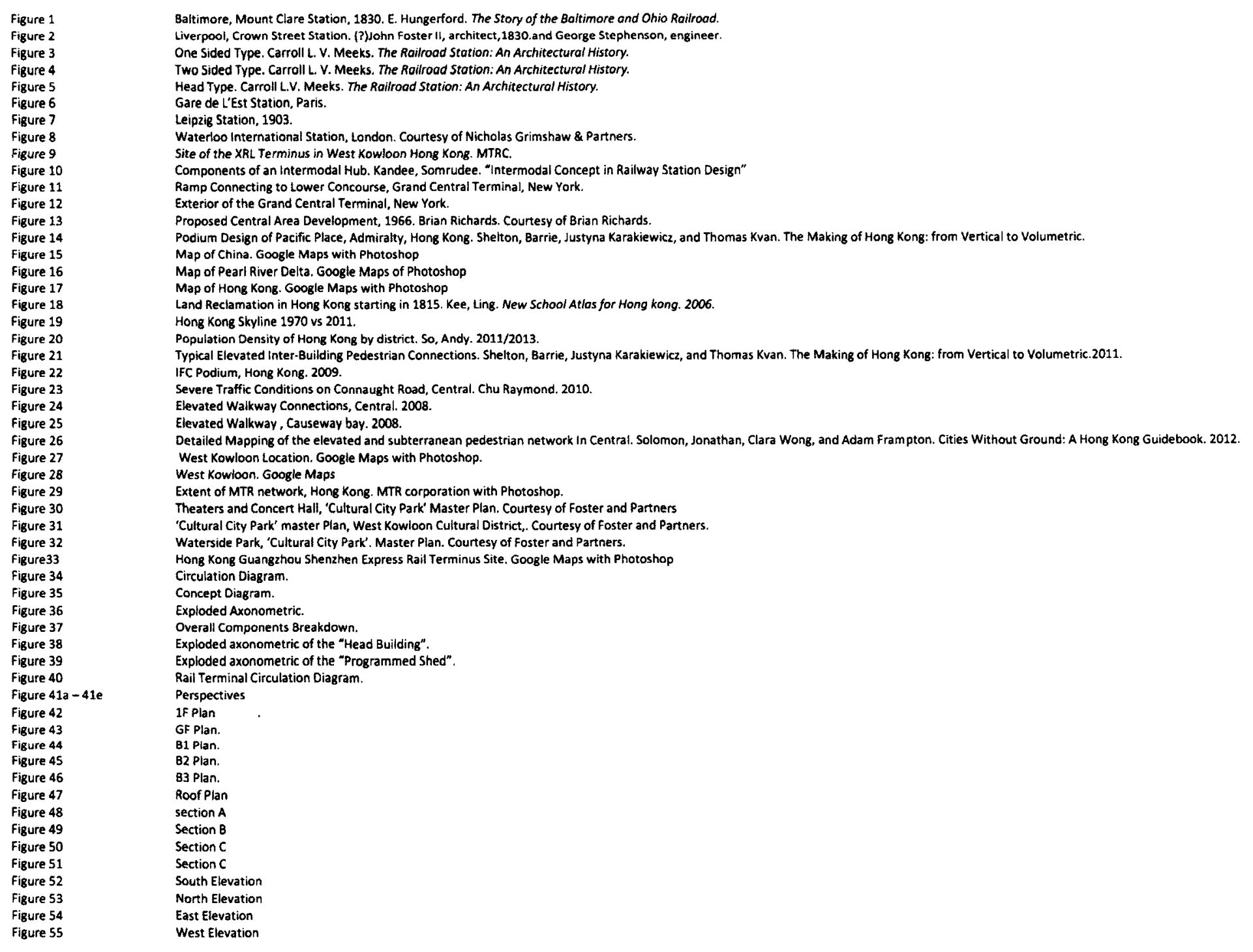




\section{Introduction}

Like many major cities around the globe, the city of Hong Kong is prone to immense population growth. But the unique problem Hong Kong faces is its inability to geographically expand. Whereas cities like New York have noticeable spread their parameters, the footprint of Hong Kong has remained modest in size since its inception as a British Colony in 1841. The built environment adapted to the massive population growth in the mid-1900s by expanding upwards in the form of vertical towers and downwards in the form of underground structures. Vast pedestrian flows and heavy vehicular traffic in Hong Kong's urban landscape necessitated a web of interweaving above and below ground connections between these towers and subterranean structures. This facilitation of circulation is the key element in much of the city's infrastructure.

In 2007, the Hong Kong government announced the Guangzhou-Shenzhen-Hong Kong Express Rail Link (XRL) between China and Hong Kong with the line terminating in the densely populated district of West Kowloon. The purpose of this line is to further enhance the linkage between Hong Kong and China. The terminal will house 15 rail lines consisting of both long haul and short haul train platforms, ${ }^{1}$ translating into an immense urban development at the very core of a landscarce city. For this reason, it is imperative for this building to become more than merely a rail terminal. While the 'facilitation of circulation' theme prevalent in much of Hong Kong's urban fabric should be carried on into the concept of this facility, other, more permanent programs, should be integrated into the building in order for it to truly transform into an urban destination.

This terminal provides an ideal opportunity for such a programmatic exploration. Its central location in the hyper dense city of Hong Kong, along with the development of a 'cultural city

\footnotetext{
${ }^{1}$ Government of Hong Kong, "Hong Kong Section of Guangzhou-Shenzen-Hong Kong Express Rail Link Project Profile". April 2008.
} $<$ http://www.epd.gov.hk/eia/register/profile/latest/esb189/esb189.pdf>. 
park' directly adjacent to it, and the increasing links between Hong Kong and mainland China, calls for the rethinking of the railway station typology as an integrated urban node.

In this project, the West Kowloon Terminal proposal will be used to explore the programmatic possibilities of what a train terminal can really be in a hyper-dense, global city. To understand better the role of the proposed building, the first section of this thesis will trace the historical development of the train station and the societal forces which have shaped it into what is today. The second chapter will provide an exploration of the cultural and geographic context of Hong Kong. Finally, the project will be outlined as both a response to historical precedent and as a strategy specific to the contemporary realities of Hong Kong. 


\subsection{The Railway Station}

Ithough this thesis calls for a reinvention of the train terminal, one cannot argue the
inherited triumph of this typology. The train station was created for a specific function: transporting population masses within and between cities. While the functional components of train stations have remained more or less constant in the past 150 years, they have undergone technological improvements to better accommodate the circulation of growing populations. For the most part, the train station is considered extremely successful in the functional sense, especially in a city like Hong Kong, where a combination of extreme population density and difficult geographical terrain yielded one of the most efficient transportation systems in the world. More specifically, the train terminal typology needs to evolve into its next iteration while retaining the essence of what has worked so well in the past. 


\subsection{The Emergence of the Railway Type}

The emergence of many building typologies often involves a number of social and political influences, but the railway station was developed in response to a specific functional need. It was a logical and necessary device following the implementation of the passenger and freight railway lines. The first appearance of a truly modern train station occurred in 1830, simultaneously in Britain and in the USA: The Crown station in Liverpool (figure 2) and the Mount Clare station in Baltimore (figure 1). These stations were established as a result of the increased popularity of the steam locomotive rail transport system invented in the $1820 \mathrm{~s}$ in England. There were, of course, no historical precedents for the train station typology before this time, so every architectural solution had to be invented anew. In other words, the railway station was an entirely unique contribution to architectural types.

Prior to the railway era, the main mode of transportation was the century old horse-drawn turn pike system which ran on a pre-set path with incremental 'inns' serving as check points. The only other specialized building that was developed for this system was the toll house which contained ticketing counters. If the Mount Clare Station and the Crown Street Station had an ancestor, it would be these toll houses. A typical feature of these early toll houses involved extending a roof across the road as a shelter for passengers; this element was later carried over to the railway station as the train shed. The Crown Station in Liverpool contained most of the components found in the modern station today: a driveway separated from street traffic for passengers arriving at the station by carriage; an entrance hall which contained ticketing booths; and waiting areas and platforms leading on to the train carriages. As primitive as this station was, it marked the beginning of the evolutionary process of the rail station typology.

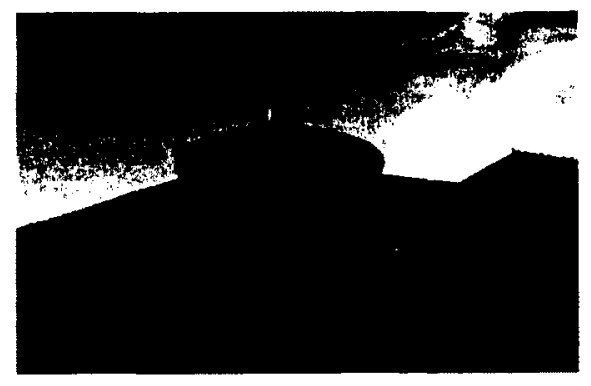

Figure 1 Mount Clare Station, Baltimore

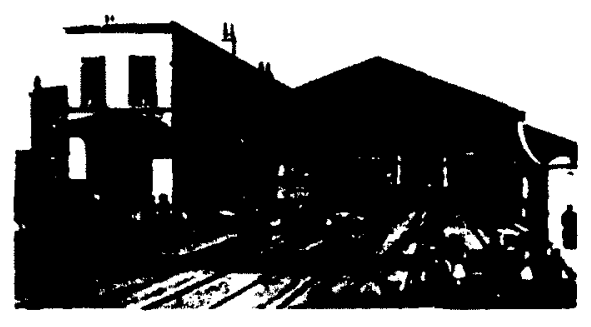

Figure 2 Crown Street Station, Liverpool 


\subsection{Standardization of Types}

"During the 1850s, the modern metropolis became a hotbed of innovation and a maelstrom of social, cultural and economic change as new notions of speed, light, power and communications were constructed. Standardized, compartmentalized notions of space and time were, in a sense, constructed through the rolling out of networks across wider and wider spaces first cities, then urban system and then international territories." ${ }^{2}$

Soon after the invention of the rail station in the 1830 s, the building type spread quickly around Europe and subsequently, the rest of the world, serving as both gateways and connections between cities. At this point, the typology began to be standardized in order to maximize efficiency. The 1850 s was a period of standardization. The Industrial Revolution, with large scale factory production and division of labor, demanded efficiency in both manufacturing and the transporting of goods. The experimental stages of the early 1800 s flourished a multitude of design approaches to the configuration of the train station. During the standardization period in the 1850 s, however, only three types in particular were most widely adopted: the one sided type, the two sided type and the head type. ${ }^{3}$

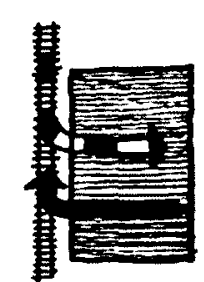

Figure 3 One Sided Type

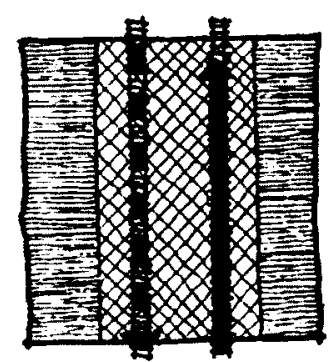

Figure 4 Two Sided Type

The one sided type is the oldest of the three, and was used for both the Mount Clare and Crown Street stations (figure 3 ). In this configuration, a building consisting of both arrival and departure halls is placed on one side of the tracks. Because this type is so simple, it never became obsolete. Many small stations today still adopt this method.

${ }^{2}$ Graham, Stephen, and Simon Marvin, eds. Splintering Urbanism: Networked Infrastructures, Technological Mobilities and the Urban Condition. New York: Routledge, 2001. Print.p.40

${ }^{3}$ Meeks, Carroll L. V. The Railroad Station. An Architectural History. New Haven: Yale U. P., 1956. Print. p.30 
In the two sided type (figure 4), the arrival and departure halls were constructed on opposite sides of the tracks, consequently separating the incoming and outgoing passengers. The main advantage of this type is that arriving trains did not hold up departing ones and both groups of passengers were able to wait longer at the platforms. The primary building containing the great hall and ticketing offices was located on the departure side.

In later years, perhaps the most widely adopted station topology was the head type station, which made use of a long rectangular building positioned perpendicularly to the tracks (figure 5). Both the arrival and departure halls were contained in the head building. The flexibility of this station type was summarized by French architect and engineer Leonce Reynaud, who would design the long-span shed of Gare du Nord in Paris in the mid-1840s:

"the advantages of the head station is that the building is clearly visible in that the same building can simultaneously contain the arrival and departure halls along with all the other required components such as waiting rooms, offices and ticket booths, the second, more obvious advantage is that the head type station frees up the entire site for podiums and tracks space allowing for future expansions."

The malleability of the head type was evident in Gare de l'Est, designed by architect Francois Duquesney in Paris 1849 (figure 6). Not long after its completion, the fast growing numbers of passengers necessitated the addition of new tracks, in which case the office spaces and waiting areas that were once located on either side of the tracks were simply transferred into the expanded head house.

\footnotetext{
${ }^{4}$ Meeks, Carroll L. V. The Railroad Station. An Architectural History. New Haven: Yale U. P., 1956. Print.p.58
}

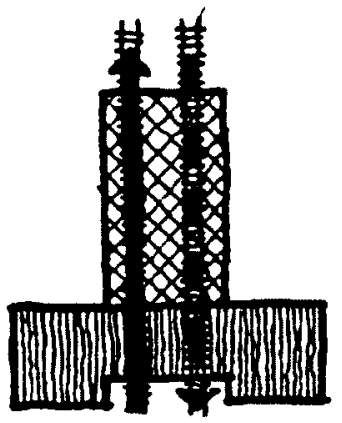

Figure 5 Head Type

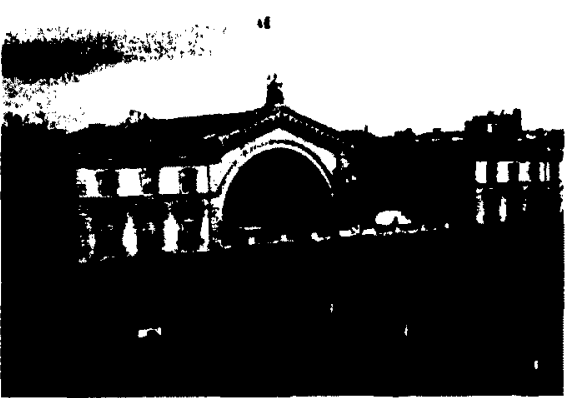

Figure 6 Gare de L'Est Station, Paris 
While many smaller modern stations still adopt the one sided or two sided station types, the head type station is still considered to be the most efficient in larger terminal buildings. The vast reclaimed land of West Kowloon, Hong Kong certainly warrants the use of a head type station. Not only would it free up the entire site for the building of the rail lines, but it would also provide a flexible catalyst on which to integrate other programs. 


\subsection{The Train Shed}

In the Liverpool Crown Station in Britain, the train shed originated as a roof sheltering the passengers on the podiums from harmful weather. As the train station type proliferated throughout Europe in the mid- $19^{\text {th }}$ century, however, the enclosing shed evolved into something much more than simply a shelter for passengers - it became an iconic representation of architectural and engineering prowess.

As newer methods of construction and materials emerged, and as demand for train service grew, railway companies took pride in their halls and invested heavily on their design. Extravagant sheds were erected in hopes of attaining wider and more daring spans. Only 25 years after the birth of the rail station typology, train shed roofs such as the New Street station in Birmingham and the Paddington Station II in London reached spans of over 200 feet by using iron for the construction framework. The daring construction of very large-span train sheds and the use of new materials, such as lightweight steel and glass become a distinctive feature of $19^{\text {th }}$ century railway architecture.

As spectacular as the sheds might have been, they were extremely expensive and time consuming to build. This led to the invention of more economical solutions in the $1850 \mathrm{~s}$, such as the Bush Shed and the Butterfly Shed ${ }^{5}$. The Bush shed, named after its inventor Lincoln Bush involves breaking down the single span roof into smaller units; each shed unit covers two lines of track and half of a platform on each side in one low reinforced concrete span. Such a shed was cheaper to build and more economical to maintain. The butterfly shed offered an even more economical solution, covering only the platform with no attempt to cover the lines or the journey from the train to the station.

\footnotetext{
${ }^{5}$ Meeks, Carroll L. V. The Railroad Station. An Architectural History. New Haven: Yale U. P., 1956. Print.p.122
} 
The introduction of these alternative solutions led to the eventual demise of the great train shed. In the end, though, it was the popularity of the head type station which ultimately deemed the train shed obsolete. Instead of a grand display of single span train sheds, the head building was emphasized; it replaced the train shed as the monumental icon of the railway station. In many cases, the train sheds were hidden away. Such as the Leipzig Station built in 1903 (figure 7). The five sheds were dropped down out of sight behind the glorified head house, hidden away out of sight.

It was not until the late 1900 s that the shed was revived. Borrowing heavily from the $19^{\text {th }}$ century stations, the daring construction of very large-spanned train sheds once again, became a distinctive feature in $20^{\text {th }}$ century station architecture. Nicholas Grimshaw's Waterloo international Terminal in London (1993) is an example of this revival (figure 8). This building boasts a 1300 foot long glass shed, and unlike the Leipzig Station, there was no attempt to hide the shed; in fact, it is the most visually dominating part of the building ${ }^{6}$. The 'hi-tech' structure is made public, commensurate to the high-speed Eurostar trains housed underneath.

In retrospect, the train shed seemed to have entered a repeated cycle, transforming first from a conspicuous icon of decadence and engineering prowess in the mid-1800s to a hidden sheltering device at the start of the 1900 s, and then again, back to its former iconic status in the late $20^{\text {th }}$ century. While these giant sheds provide a gravity-defying spectacle, the problem of impracticality recognized in the 1850 s still persists. In addition to being extremely expensive to build, extravagant sheds take up large portions of land which could otherwise be used for additional programs. This is especially true in cities where land is scare and populations dense

${ }^{6}$ Binney, Marcus. Architecture of Rail: The Way Ahead. London: Academy Editions, 1995. Print. p.12

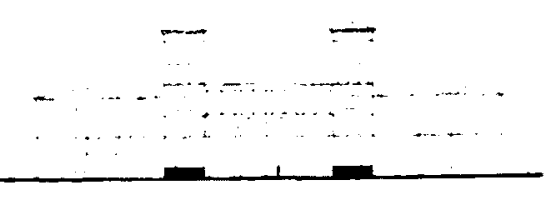

Figure 7 Leipzig Station, 1903

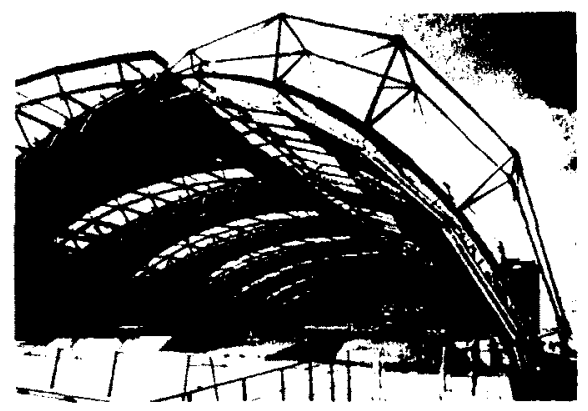

Figure 8 Waterloo International Station, London

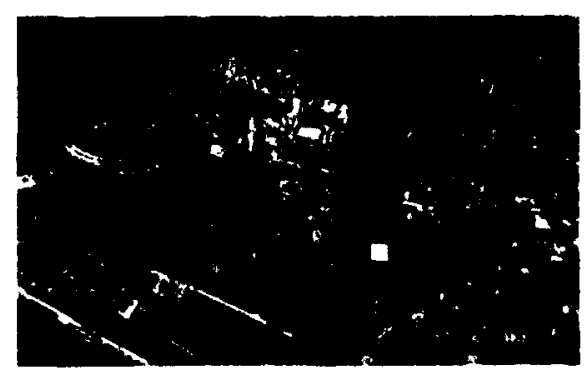

Figure 9 Site of the XRL Terminus, West Kowloon Hong Kong 
(figure 9). The rise of 'global' Asian cities, not to mention the "instant cities" being built in China, calls into question what kinds of transportation networks - and architecture - will be built. Many of these cities have invested heavily in airports designed by "star architects". Nevertheless, daily life continues with the use of trains and buses. Is, then, the revival of the grand railway shed the correct way to organize these cities? Or is it a need for a new kind of "head"-type station? Or will it be something else? The dense urban environment of Hong Kong is facing these questions, as the city continues to develop its transportation infrastructure within tight spatial and cultural constraints. 


\subsection{Intermodal Transport Hub}

"The Intermodal transport hub is the concept of transporting passengers in two or more different modes in such a way that all parts of transportation process, including the exchange of information, are efficiently connected and co-ordinate."7

In the past, train stations were preferred to be located on branch lines extending from the urban core in order to economize land costs. Modern train terminals however, call for a much more intimate integration with the urban fabric; they became a single hub for interfacing and interconnecting with a multitude of inter-city and intra-city transport systems. ${ }^{8}$ Other transportation systems such as local city bus stations and subway connections all have to be housed under a single facility. This is greatly beneficial to public transportation providers as they can benefit from the efficiencies of shared costs and operation infrastructure. Public transportation services benefit from smoother intermodal interfaces and travel route connection opportunities which tend to generate higher ridership. And finally, the passengers benefit greatly from improved system wide connectivity and the greater convenience this affords in making connections among local, regional or intercity travel.

The basic functions of an intermodal transport hub can be broken down into four general components: Core areas, Transit areas, Peripheral areas and Administrative areas (figure 10). Core Areas contain passenger processing programs such as ticketing, information baggage handling, reclaiming and waiting. Transit areas connect the core areas to the different modes of

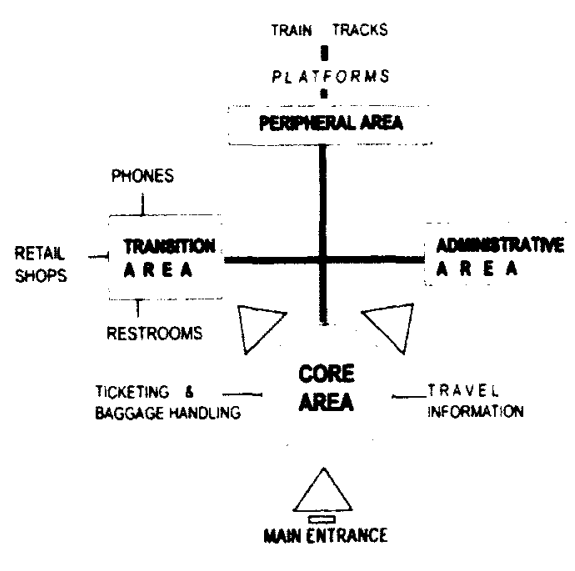

Figure 10 Components of Intermodal Transport Hub

\footnotetext{
${ }^{7}$ Muller, Gerhardt, and John H. Mahoney. Intermodal Freight Transportation. Westport, Conn. (P.O. Box 2055, Westport 06880): Eno Foundation for Transportation, 1989. Print. p.15

${ }^{8}$ Henry, Lyndon, and Marsh, David. "Intermodal Surface Public Transport Hubs: Harnessing Synergy for Success in America's Urban and Intercity Travel". 2008. < http://www.vtpi.org/henry_marsh.pdf>
} 
transportation. They contain secondary, but often essential facilities such as restrooms, telephones and commercial spaces. Peripheral areas support circulation outside the main buildings, and include platforms, tracks and vehicle service spaces. Administrative areas control both traffic and station types that provide complex arrangements for handling a large number of passengers. These areas can be isolated from the other facilities or inserted among them. ${ }^{9}$

The famed Grand Central Terminal of New York City perhaps best exemplifies the practicality of in the intermodal hub (figure 12). Originally built in 1871 , the use of multiple levels to handle the complex circulation problems was carried further than in any other station previously (figure 11). The multileveled tracks systems separated the express trains on the upper levels from the suburban trains below and each set of tracks was provided with a concourse of its own, so that in effect two independent stations were layered on top of one another. Ramps were used generously, not only to transfer passengers to and from the platforms but also to get them in and out of the station. There are connections to all the neighboring streets and to subways and shuttle trains. All this was achieved without forcing passengers to walk excessive distances. ${ }^{10}$

The massive pedestrian traffic flow generated by the superimposition of multiple transportation networks has attracted a myriad of non-transport related programs. ${ }^{11}$ it was an obvious opportunity to remake the train station into a mixed-use center of multiple activities while stil accommodating train and bus services. In fact, the high pedestrian flow makes train stations lucrative locations for retail shops and restaurants.

\footnotetext{
${ }^{9}$ Kandee, Somrudee. "Intermodal Concept in Railway Station Design", < http://www.bu.ac.th/knowledgecenter/epaper/ian june2004/somruedee.pdf>

10 Powell, Ken. Grand Central Terminal: Warren and Wetmore. London: Phaidon, 1996. P.35-36

${ }^{11}$ Henry, Lyndon, and Marsh, David. "Intermodal Surface Public Transport Hubs: Harnessing Synergy for Success in America's Urban and Intercity Travel". 2008. <http://www.vtpi.org/henry_marsh.pdf>
} 
Such extensive integration of different transportation systems requires intricate circulation networks. Many studies have been conducted to maximize efficiency in the circulations of intermodal transport hubs. A generic solution was presented by urbanist Brian Richards in 1966.

12 In it, he illustrated a typical central area development scheme which utilized a continuous 'pedestrian-moving belt' ${ }^{13}$ as the central organizing element, with a glass canopy over top so that light fills the spine. Adjacent to it are buildings, office lobbies, and transport interchange points (Figure 13). Richard was, importantly, a member of Team 10, the group of post-war avant-garde architects that sought to create cities open to 'growth and change'. The need for 'flexible' solutions was a reaction to the hierarchical division of space demanded by the International Congress for Modern Architecture (CIAM) in its famed Athens Charter of 1933. Yet as one of the four categories for designing cities, CIAM would include "transportation". Thus the visionary projects for "linear cities" by Le Corbusier as well as the Russian Constructivists, in which the endless extension of an ideal city (designed according to the remaining CIAM categories of work, dwelling, and recreation) was based on transportation system -specifically, the railroad. In short, both the pre- and post-war avant-garde saw transportation technologies as ways to imagine the future city.

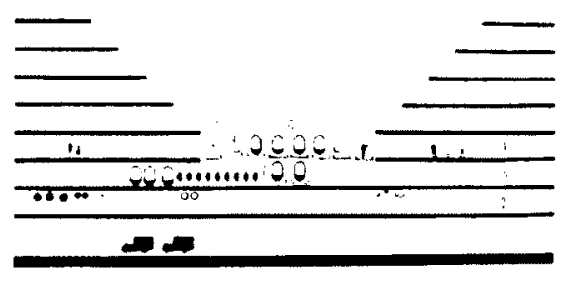

Figure 13 Proposed Central Area Development, 1966. Brian Richards

\footnotetext{
12 Wolf, Peter. The Future of the City: New Directions in Urban Planning. New York: Watson-Gultill Publications, 1974. Print.p78-79

${ }^{13}$ Wolf, Peter. The Future of the City: New Directions in Urban Planning. New York: Watson-Gultill Publications, 1974. Print.p78-79
} 


\subsubsection{Intermodal Transport Hubs in Hong Kong}

The concept of Intermodalism is applied vigorously in Hong Kong. In many North American cities where land is abundant, the form of cities and towns is determined by the road networks. In Hong Kong, the location of new town developments is determined entirely on the extent of the local train network.

"The most important difference between road and rail development is the impact each has on land use. Both enhance access to a region, which in turn can lead to intensified land use and higher property values. Rail developments however, can induce concentrated residential and commercial development which increase land value and minimizes the space utilized." ${ }^{14}$

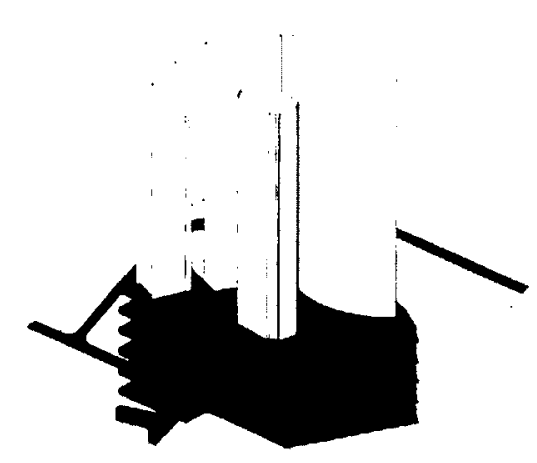

Figure 14 Podium Design of Pacific Place, Admiralty Hong Kong

The Mass Transit Railway Corporation(MTR) plays a vital role on the establishment of new communities centered around rail access. The typical strategy in the planning of these Intermodal hubs involves positioning a bus and/or a train station under the extensive mass of a shopping podium, which in turn sits beneath a cluster of tall residential towers (figure 14). ${ }^{15}$ These transit oriented developments not only provides more convenient access for residential and commercial developments, but they also create lucrative investment opportunities for large developers.

\footnotetext{
${ }^{14}$ Moore, James A. , Juliet M. Johnson, State Transportation Policy Initiative, op.cit.

${ }^{15}$ Shelton, Barrie, Justyna Karakiewicz, and Thomas Kvan. The Making of Hong Kong: from Vertical to Volumetric. New York, NY: Routledge, 2011. Print. p.123
} 


\subsection{Hong Kong : A Culture of Transition}

"The city (Hong Kong) is not so much a place as a space of transit. It has always been, and will perhaps always be, a port in the most literal sense-a doorway, a point in between..."

7

he words 'gateway' and 'transitory' are embedded deeply into the identity of Hong Kong. At the macro-scale, its coastal location on the Pearl River Delta presented Hong Kong with a vital entrepreneurial role between China and the rest of the world (figure $15-17$ ). At the micro-scale, the immense population of more than 7 million people is constantly making inter or intra city commutes. In many ways, the experience of being in Hong Kong is not dissimilar to that of being in a busy railway terminal. Like passengers rushing between train podiums and arrival/departure halls, massive throngs of Hong Kong citizens are perpetually transiting between destination points. And like a railway station, the city of Hong Kong mostly serves as a gateway between two destinations.
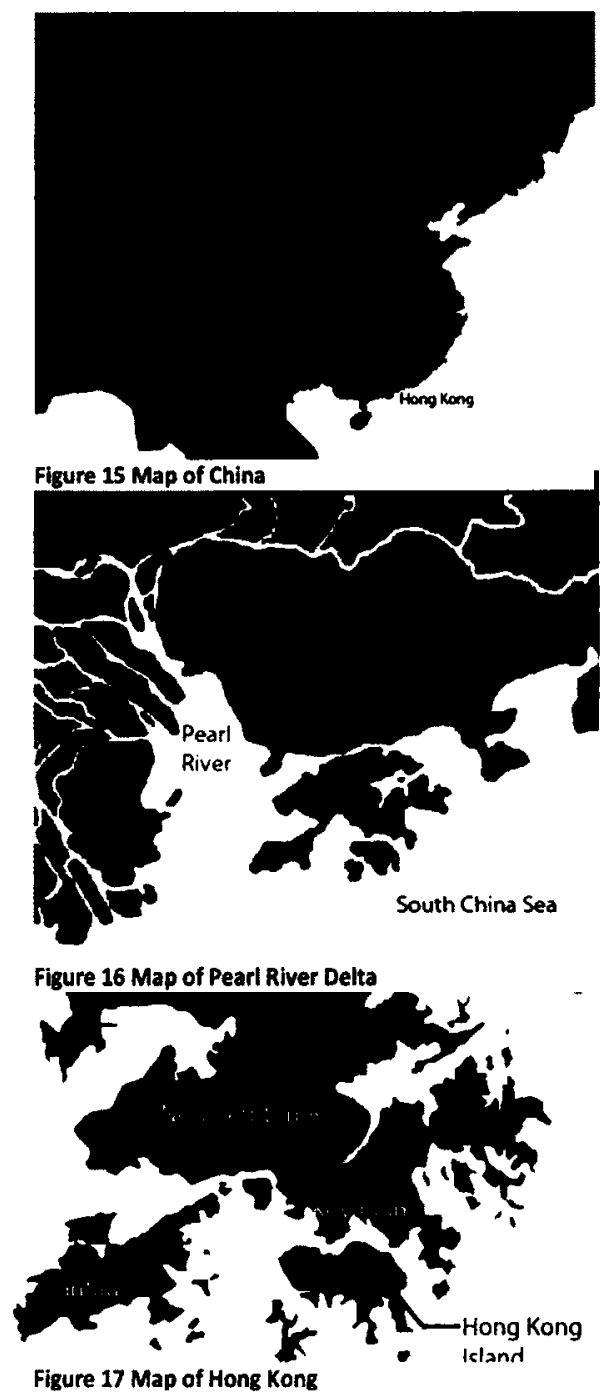

${ }^{16}$ Abbas, M. A. Hong Kong: Culture and the Politics of Disappearance. Minneapolis: University of Minnesota, 1997. Print. p.4 


\subsection{Identity of Transition}

The sense of temporality is very strong in Hong Kong. From its cultural identity to its vibrant street circulation, nearly every aspect of Hong Kong is characterized by a sense of transition. This transitional culture partly emerged from its historical development. It is difficult to define a distinct set of characteristics for Hong Kong because its cultural identity is in a state of perpetually reinventing itself. Although Hong Kong has earned its place as a major financial center on par with New York City and London, it has barely left its youth as a city when measured against the comparatively ancient American and European cities. Hong Kong began as a fishing village until it was operated as a British Colony in 1841 and more recently as a Special Administrative Region of China after the 'handover ceremony in $1997^{\prime 17}$. However, unlike many other colonial cities in India and Africa, Hong Kong lacks a pre-colonial history, or at least a history that is relevant to what Hong Kong has become today. The 99 years of British rule was the first time Hong Kong had to invent a culture for itself. ${ }^{18}$

It would be misleading to consider the 'handover' ceremony of 1997 as a reunification between Hong Kong and China. Rather, the year 1997 marked the end of British Colonialism in Hong Kong; the end of the very brief first chapter of Hong Kong's colonial history. Although in recent years, conspicuously stronger economic ties have been established with China, Hong Kong remains culturally and politically distant from the mainland even after 15 years. Since then, there have been a large decrease of western expatriates and a large increase of mainland Chinese, resulting in many Hong Kong residents feeling that the city's international quality has declined ${ }^{19}$, while its

17 Tsang, Steve Yui-Sang. A Modern History of Hong Kong. London: I.B. Tauris, 2004. Print.p15

18 Abbas, M. A. Hong Kong: Culture and the Politics of Disappearance. Minneapolis: University of Minnesota, 1997. Print. p.2

${ }^{19}$ Martin, Michael F. "Hong Kong: Ten Years After the Handover." CRS Report for Congress(2007): 30-31. Print. 
Chinese cultural attributes are taking over. With the provision of better connectivity between Hong and China such as the XRL and the more recent 'Hong Kong Mainland China driving scheme $^{20,}$, many local residents feel threatened jobs on both ends of the salary spectrum are increasingly being filled by Mainland Chinese. Once again, Hong Kong's cultural and political identify enters the process of re-invention.
The Hong Kong mainland China driving scheme is a cross-border driving scheme established in 2012, which allows drivers of cars with primary registration in mainland china to drive directly in to Hong Kong. 


\subsection{Shape Shifting Shoreline and Built Environment}

Along with the 'floating' identity of Hong Kong, the city's physical form is also in a constant state of transition. Due to Hong Kong's restrictive geographical location between the Pacific Ocean to the south and the Chinese border to the north, the city resorted to large scale landfill undertakings in order to cope with the massive population growths of the mid-twentieth century. Large-scale landfill projects have extensively altered the coastline of Hong Kong and entire districts have been built on reclaimed land (figure 18). Between 1815 and 1945, an area of 60 square kilometers was built into the harbour, and since the Second World War, a further thirty square kilometers was added to bring the total to almost 100 square kilometers of reclaimed land. During the 1950 s and 1960 s, large scale reclamation projects were carried out in Causeway Bay and North Point on Hong Kong Island, in Kowloon, Kwun Tong and in Cheung Sha $W_{a n}{ }^{21}$. The latest large scale project was the 'Hong Kong Airport Core Programme' undertaken in the early 1990s, which was a series of 10 support infrastructural projects for the new Hong Kong International Airport in Chek Lap Kok ${ }^{22}$. Among these ten projects was the West Kowloon Region which was required for the construction of an express highway connecting the city with the new airport.

\footnotetext{
${ }^{21}$ Graf, Arndt, and Beng Huat. Chua, eds. Port Cities in Asia and Europe. London: Routledge, 2009. Print. p 65

22 "Airport Core Programme highways Projects". Government of Hong Kong.. < http://www.hyd.gov.hk/eng/major/airport/index.htm>
} 


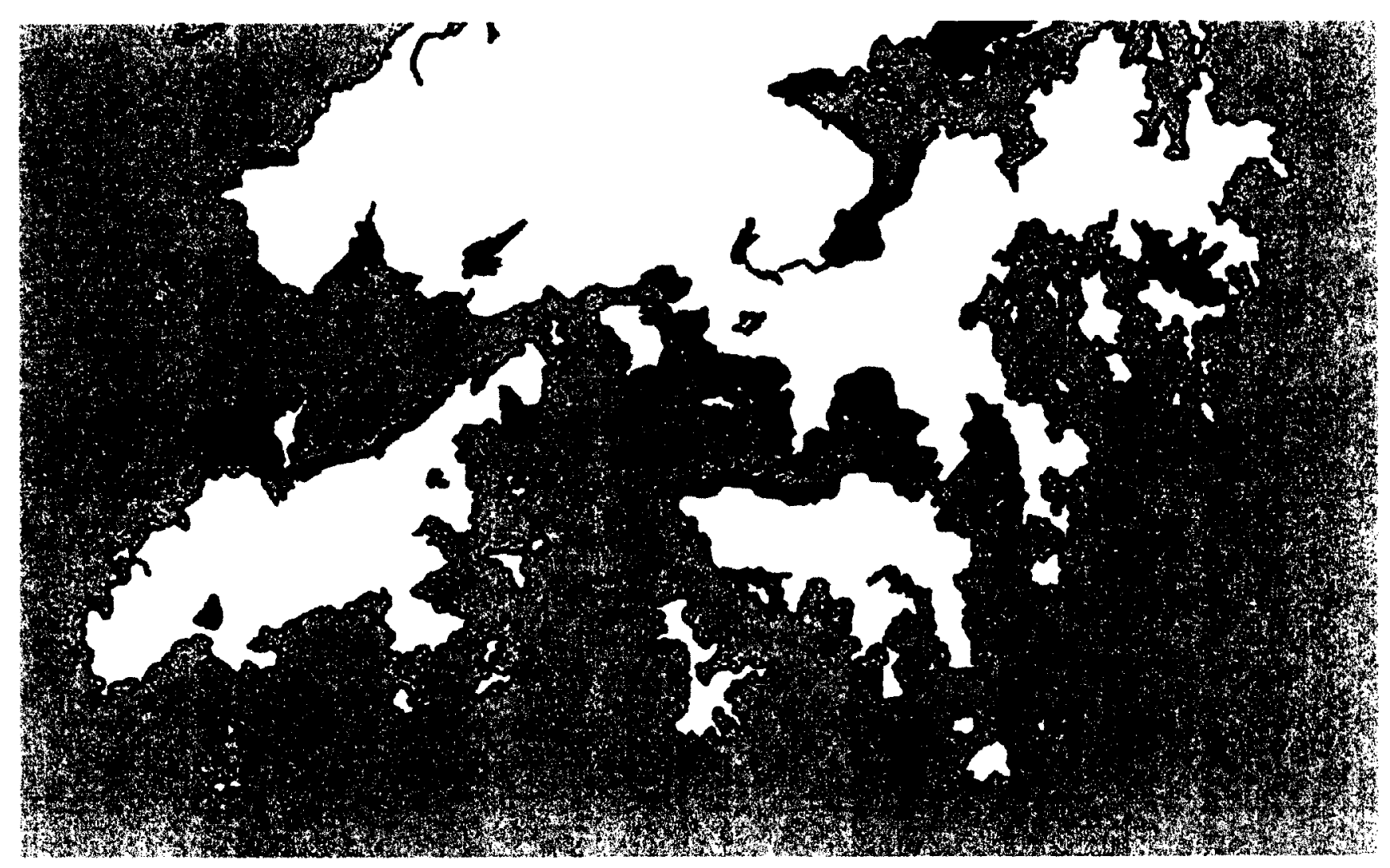

Figure 18 Land Reclamation in Hong Kong starting in 1815: Grey(built), red (proposed or under development) 
Like its morphing shoreline, the skyline of Hong Kong is constantly shifting as well (figure 19). With the exception of a few signature buildings, the landscape of Hong Kong is constantly being reshaped as a result of a combination of extreme land price fluctuation, land speculation and mega corporations hunting for prime spaces. This is especially true in premium districts such as Central and the now growing Kowloon West. The lifespan of a building has little to do with its structural integrity, but instead depends entirely on its potential economic return. The Ritz Carlton Hotel in Hong Kong provides an ideal example. When the building was completed in 1993 on a prime Central site not far Sir Norman Foster's Hong Kong Shanghai Bank building, it was sold to a multinational consortium. Despite the fact that it was a brand new building at the time, the new owners seriously considered demolishing the hotel immediately to make way for a potentially higher revenue office building. A short 15 years later, the demolition plans were executed.

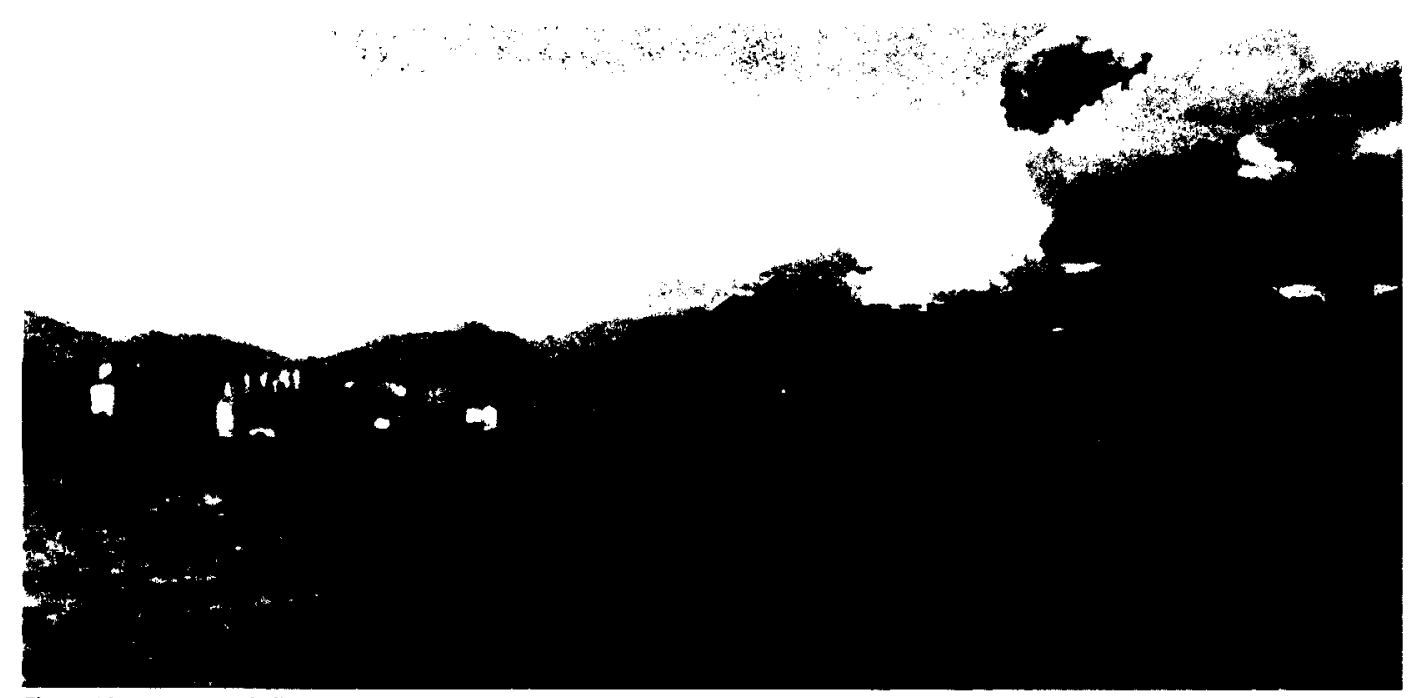

Figure 19 Hong Kong Skyline 1970 vs 2011 


\subsection{Hyper Density}

One of the defining characteristics of Hong Kong is its large and densely-housed population. The city's density ratio of some 6300 people per square kilometer ${ }^{23}$ may appear insignificant compared to other large Asian cities such as Macau $\left(18000 \mathrm{p} / \mathrm{km}^{2}\right)^{24}$ and Mumbai $\left(22937 \mathrm{p} / \mathrm{km}^{2}\right)^{25}$, but this is largely due to the uneven fluctuating profile of the Hong Kong terrain, which forces the concentration of population in certain districts. The population of the central business district of Hong Kong Island (Central district and Western District), for example, sits at $20100 \mathrm{p} / \mathrm{km}^{2}$ while the eastern industrial district of Kwun Tong in Kowloon climbs to a astounding $52000 \mathrm{p} / \mathrm{km}^{2}$ (figure 20). In sharp comparison, the density ratio of Ottawa is only at $316.6 \mathrm{p} / \mathrm{km}^{2}$. $^{26}$

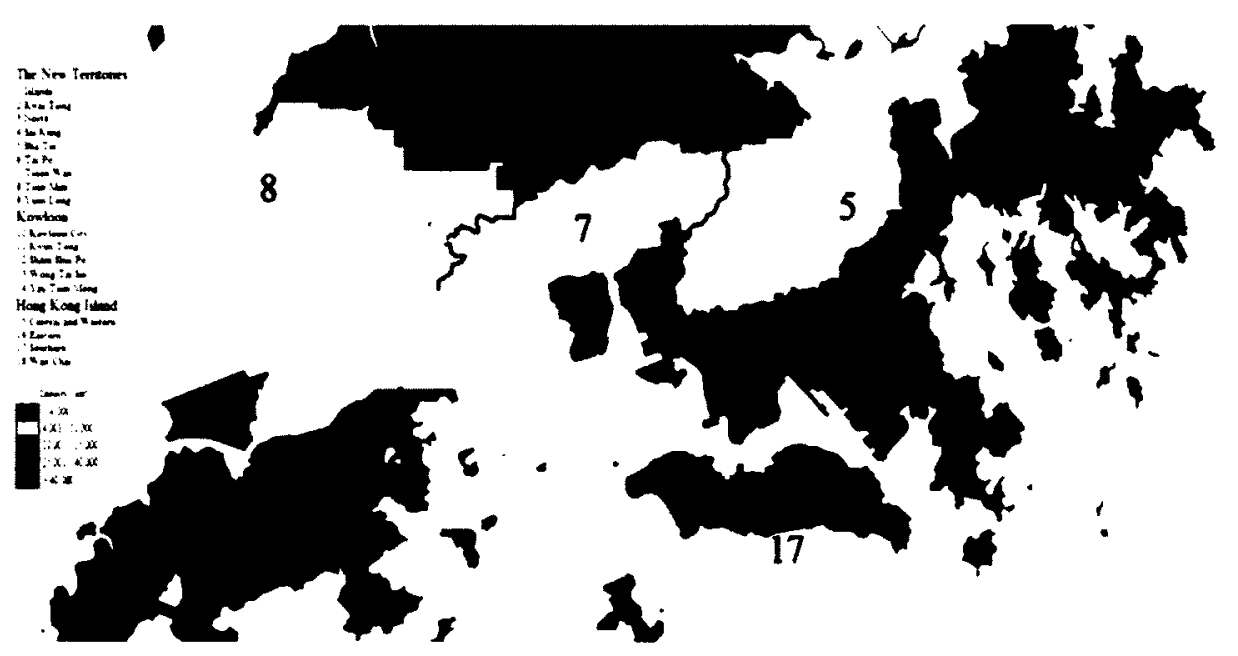

Figure 20 The 18 Districts of Hong Kong and Population Density of Hong Kong by District.

\footnotetext{
23 "Population Density by Area". Census and Statistics Department, Hong Kong Government. 2009.

24 "Population estimate of Macao (2nd Quarter/2010) ('000)". Statistics and Census Service. Macao SAR Government, 2010

25 "Ranking of districts of Maharashtra by population size 2011". Census India.gov.in, 2011

26 "Population and dwelling counts, for Canada and census subdivisions (municipalities), 2011
} 
The reason for Hong Kong's immense population is due to huge influxes of foreigners during the developing years of the city while major civil unrests occurred in China. Much of the population today, therefore, is made up of refugees from China and expatriates from western countries. Immigrants to Hong Kong have been mainly Chinese, and the city's rapid growth was in part due to its magnetic as a center of trade. But it also had much to do with the push from various political upheavals in the region that resulted in hundreds of thousands of refugees from China and elsewhere pouring into the region.

The first major civil unrest in China that attracted people to Hong Kong occurred soon after its inception during the 1850-1861 Taiping Rebellion. Within less than twenty years, there were over 100,000 people in Hong Kong, and over a quarter of a million before the end of the nineteenth century. This growth outpaced that of several cities of Victorian Britain during their years of industrialization. However, this first period of growth is insignificant compared to the population growth experience by Hong Kong from 1945 to 1951 following the period of Japanese occupation during the Second World War. During this period, the population grew by 210 percent, from 650,000 to 2.02 million, after which the city continued to grow by between onehalf and one million people per five year period until the mid-1960s ${ }^{27}$. Today the small city of Hong Kong houses a population of over 7 million people. ${ }^{28}$
The Taiping Rebellion was a widespread civil war in southern China from 1850 to 1864 , led by heterodox Christian convert Hong Xiuquan, against the ruling Manchu-led Qing Dynasty. Approximately 20 million died in this war.

The Japanese occupation of Hong Kong began after the Governor of Hong Kong surrendered the territory of Hong Kong to japan on $25^{\text {th }}$ December 1941. The occupation lasted for more than 3 years until the Japanese surrendered in 1945

\footnotetext{
27 Davis, Sydney G. Hong Kong in Its Geographical Setting. London: Collins, 1976. Print. Chapter 5

28 "Population Density by Area". Census and Statistics Department, Hong Kong Government. 2009. Retrieved 4 October 2010.
} 


\subsection{Multi Layered Infrastructure}

In the face of hyper population densities and constant restructuring of the city core, vast networks of elevated and subterranean infrastructure have emerged, drastically transforming Hong Kong streetscape. Much of the city is built on steep slopes, with occasional dramatic drops in elevation from one block to the next. Due to this inherent 'slopey' geographical configuration and its overwhelmingly dense population, Hong Kong's network of streets plane have evolved into an intricate three dimensional web. Therefore, the vigorous street life of Hong Kong is not only prevalent on the ground plane, but also within extensive networks of elevated foot bridges and subterranean tunnels. This 'groundless' condition ${ }^{29}$ is one of the unique features of Hong Kong that is distinct from other cities; the ground plane merely serves as one of many layers of public activities (figure 21). In many parts of Hong Kong, these networks of interconnected malls, office towers and residential buildings have become the main form of pedestrian passage. Pedestrians are able to walk from the western end of the Hong Kong Island all the way to the east end without ever setting foot on the ground.

One the one hand, these infrastructural networks greatly facilitates the flow of pedestrian travel. On the other hand, they strip the Hong Kong urban fabric of the traditional figure-ground relationships which help shape urban spaces (i.e. axis, edge, center). As Jonathan D. Solomon puts it, "the perception of distance and time is distorted through compact networks of pedestrian infrastructure, public transport and natural topography in the urban landscape ". ${ }^{30}$ Moreover, due to the convenience and accessibility of these alternative infrastructures, the ground street level is often neglected as a place for social activities. New mega commercial

\footnotetext{
${ }^{29}$ Shelton, Barrie, Justyna Karakiewicz, and Thomas Kvan. The Making of Hong Kong: from Vertical to Volumetric. New York, NY: Routledge, 2011. Print. p. 132-133

${ }^{30}$ Solomon, Jonathan, Clara Wong, and Adam Frampton. Cities Without Ground: A Hong Kong Guidebook. ORO Editions, 2012. Print. p. 3
} 
developments like the International Finance Center in Central are entirely built on a podium structure one floor above street level while the ground floor is reserved for support facilities (figure 22).

Whereas private car ownership is almost a necessity in many North American cities, the residents of Hong Kong rely on public transportation due to extremely high vehicle taxation ranging anywhere from $35 \%$ to over $100 \%{ }^{31}$. Only $11 \%$ of Hong Kong residents own private vehicles ${ }^{32}$, which is significantly less than New York City $\left(48 \%{ }^{33}\right)$. However, because of the city's geographical restrictions, which offer limited land for the expansion of road networks, traffic congestions are extremely severe in Hong Kong (figure 23). For this reason, the underground subway system (MTR) is preferred over vehicular transportation. Over 4 million trips ${ }^{34}$ are made through the MTR system on a daily basis, making it the most widely used mode of transportation in Hong Kong.

For this reason, a typical resident of Hong Kong would spend a large portion of their day in these above ground and subterranean infrastructures commuting to and from work and between other destinations (figure 24-25). Mark Augé's concept of 'non-places' provides a fitting description of these distorted transitory spaces absent of social activities:

"If a place can be defined as relational, historical and concerned with identify, then a space which cannot be defined as relational, or historical, or concerned with identify will be a non-place...a world where a dense network of means of transport which are also inhabited spaces is developing; a world thus

\footnotetext{
31 "Legco Doubts on Car Curbs", South China Morning Post, 3 June 1982

32 "Transport, Communications and Tourism", Census and statistics Department. 13 October 2010.

33 Greenman, Catherine. "Choreographing the Dance of Traffice Lights". The New York Times. 21 July 2011

34 "MTR Patronage Updates". MTR Corporation Limited. 2011.
}
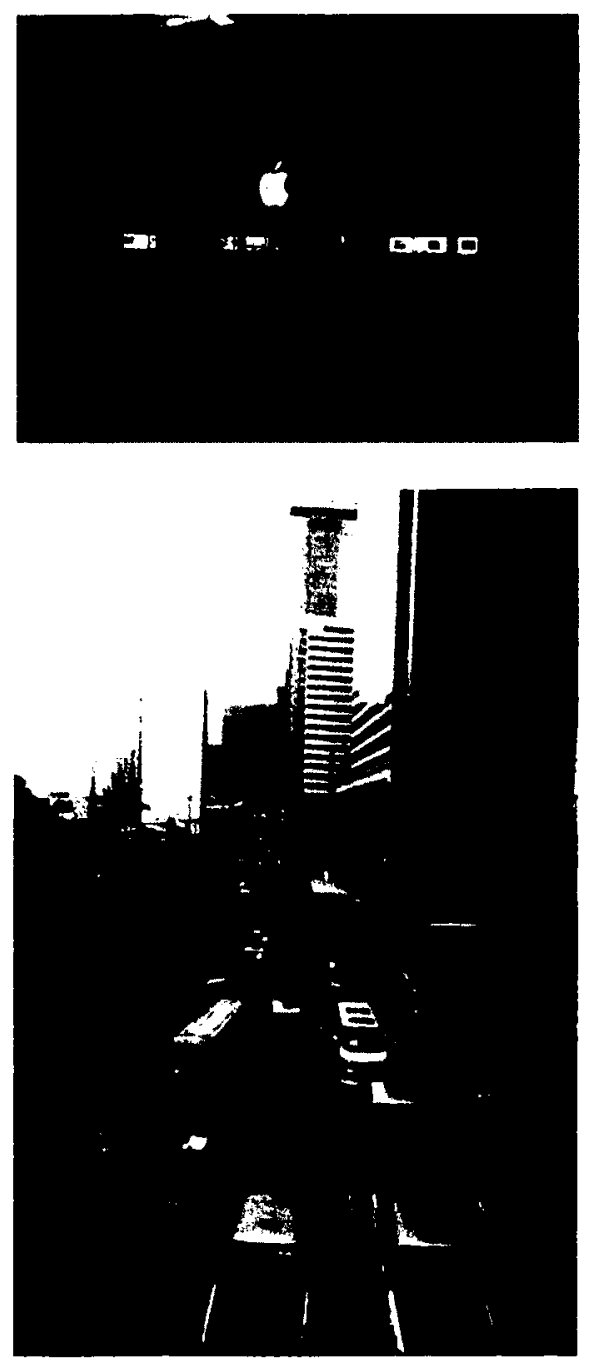

Figure 23 Severe Traffic Conditions on Connaught Road, Central, Hong Kong 
surrendered to solitary individuality, to the fleeting, the temporary and

ephemeral "35

This condition is most evident in the financial districts where a combination of densely packed office towers and heavy vehicular traffic flow necessitates this kind of elevated inter-building connections. In the past, the Central district on Hong Kong Island was considered the central business district of Hong Kong. However, in recent years, due to the lack of available space on the island, the financial center has expanded across the Victorian Harbor to the land filled-site of Kowloon West.

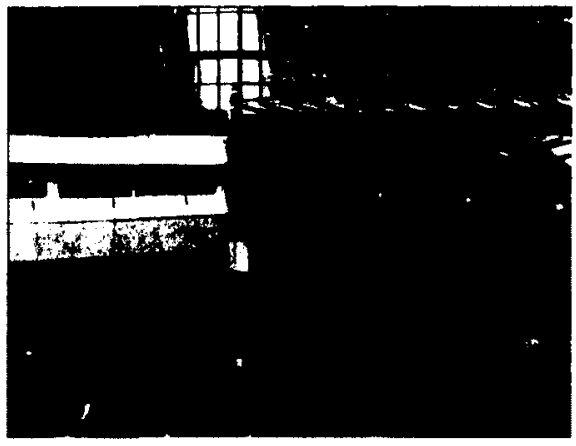

Figure 24 Elevated Walkway, Causeway Bay, Hong Kong

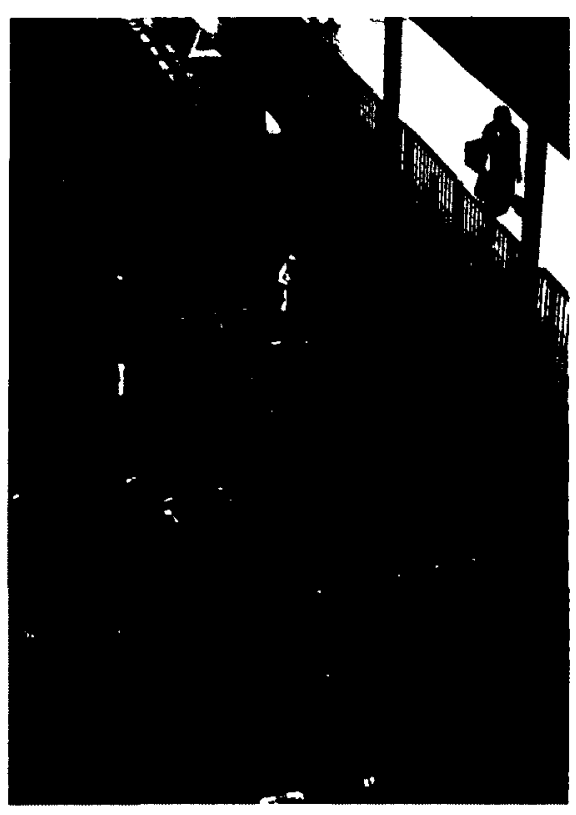

Figure 25 Elevated Walkway, Causeway Bay, Hong Kong

\footnotetext{
${ }^{35}$ Augé, Marc. Non-places: Introduction to an Anthropology of Supermodernity. London: Verso, 1995. Print. p63.
} 


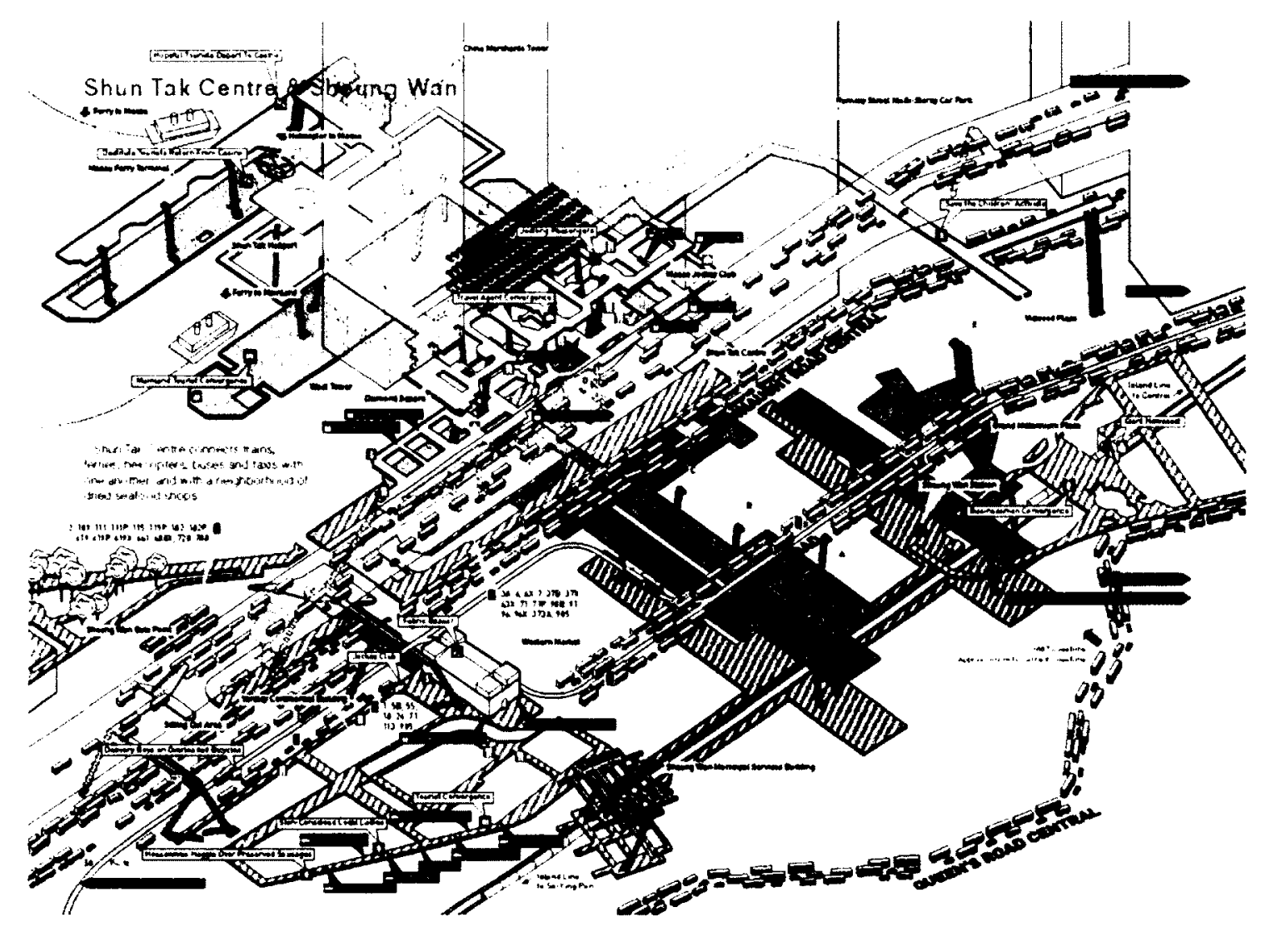

Figure 26 Detailed mapping of the elevated and subterranean pedestrian network in Central, Hong Kong by Jonathan Solomon. 


\subsection{West Kowloon Region Hong Kong}

The West Kowloon region is a peninsula located on the west end of Kowloon at the edge of the Victoria Harbor. It is entirely a land filled stretch of land which was opened to development in the late 20th century. It has been zoned for mixed commercial, residential and leisure development (figure 27-28). ${ }^{36}$

Over the past two decades, strong efforts have been made by the Hong Kong government to relieve the population density of Hong Kong and Kowloon by expanding the MTR rail network northward towards New Territories near the Chinese Border (figure 29). With the population spread evenly among Hong Kong, the Kowloon peninsula has consequently become the most central place in Hong Kong. This makes it the ideal location for the new Guangzhou-ShenzhenHong Kong express rail link Terminal. This site has also attracted many large corporations to develop luxury residential and commercial developments.

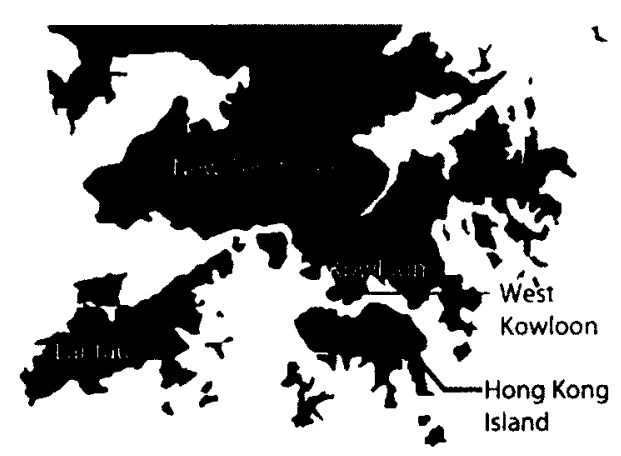

Figure 27 West Kowloon Location

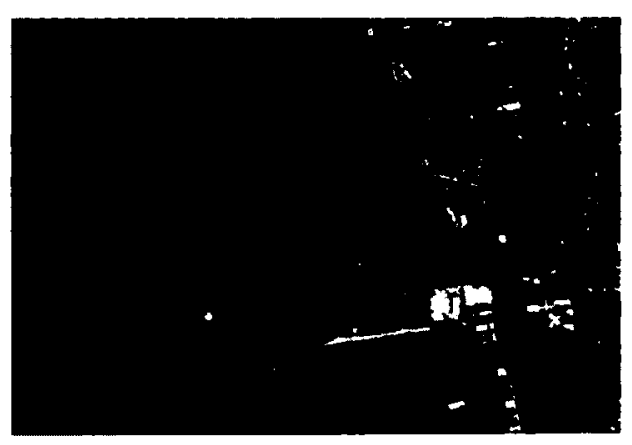

Figure 28 West Kowloon

\footnotetext{
${ }^{36}$ West Kowloon Cultural District Authority. "Background of WKCD". < http://www.wkcdauthority.hk/en/background of wkcd/index.html>
} 


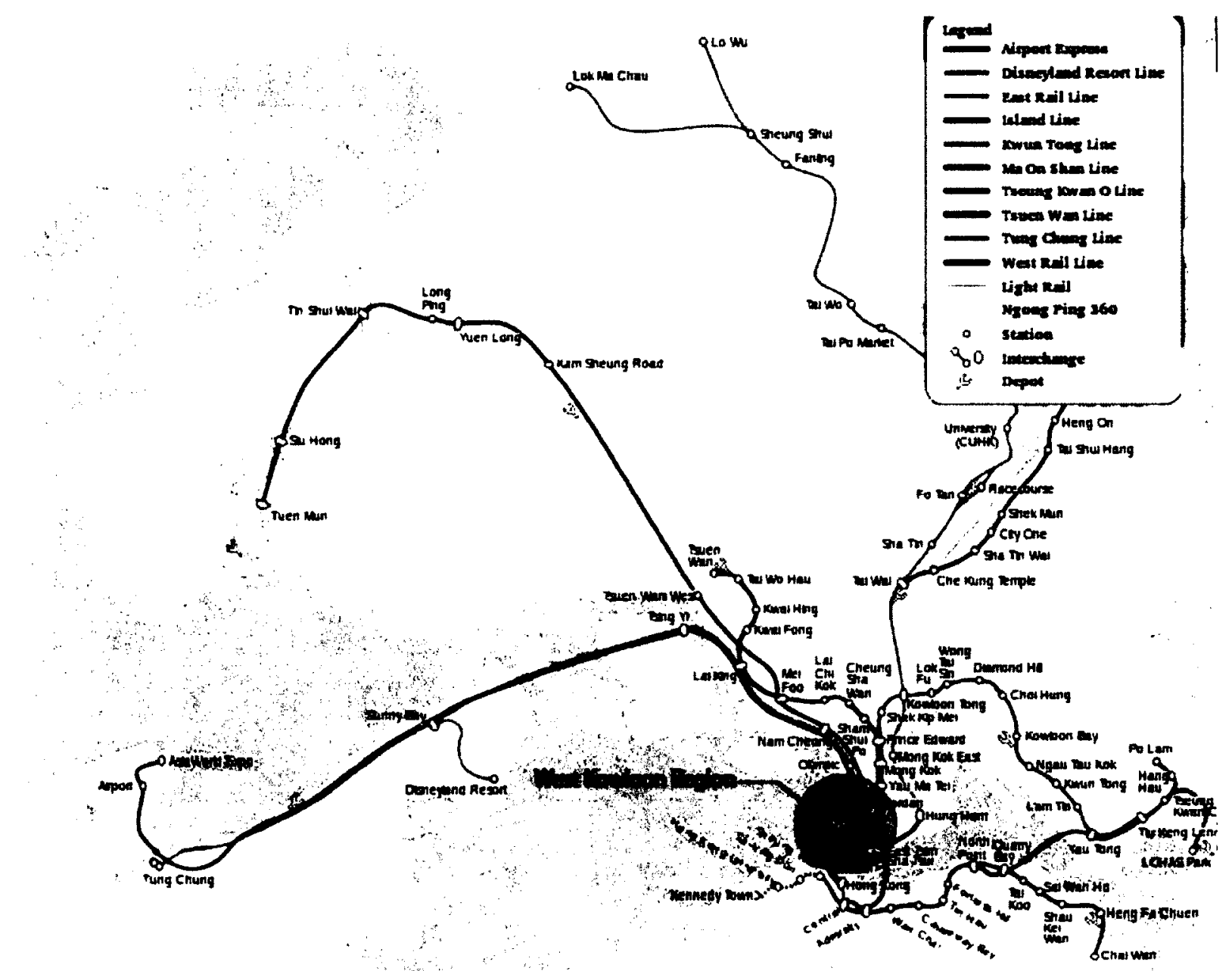

Figure 29 Extent of MTR network, Hong Kong 
Along with being a center of financial activity, the Hong Kong government also planned to use this site to create a cultural hub. A survey taken by the Hong Kong Tourism Board in 1996 revealed that many of the tourists thought Hong Kong was lacking in cultural opportunities. A suggestion was subsequently made to the Legislative Council of Hong Kong proposing that new venues for cultural events be established. In the Chief Executive's Policy Address of 1998, Tung Chee Hwa (then Chief Executive of Hong Kong), announced the establishment of the West Kowloon Cultural District, in hopes to develop West Kowloon, and by extension, Hong Kong into the new hub for Culture and Art of Asia. ${ }^{37}$

A competition was subsequently held to design the master plan for the West Kowloon Cultural District and was won by Sir Norman Foster. His design includes a new modern art museum, numerous theatres, concert halls and other performance venues. In addition to these programs, this 'Cultural City Park' scheme will also include a park next to the Victoria Harbour (figure 30 32).

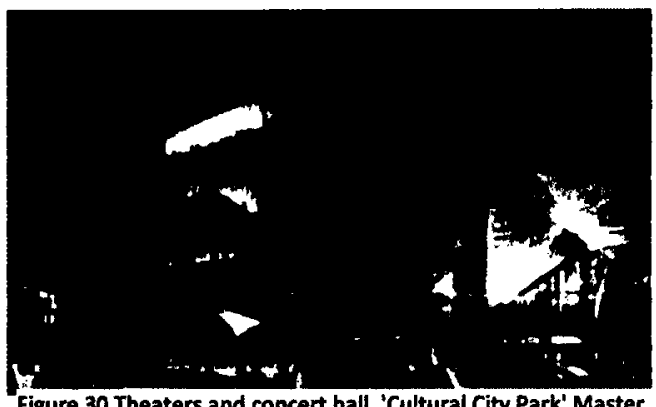
Figure 30 Theaters and concert hall, 'Cultural City Park' Master Plan by Sir Norman Foster

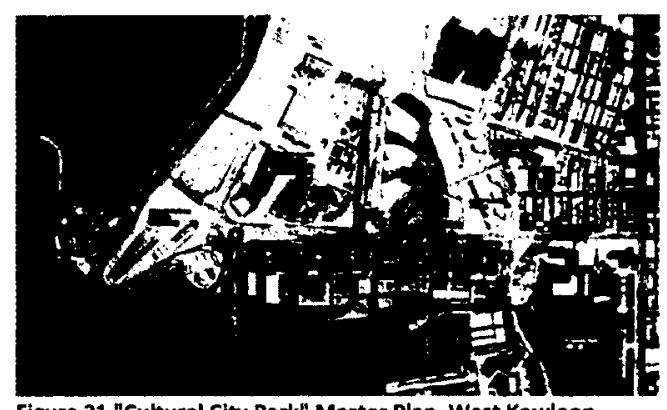

Figure 31 "Cultural City Park" Master Plan, West Kowloon Cultural district, Sir Norman Foster

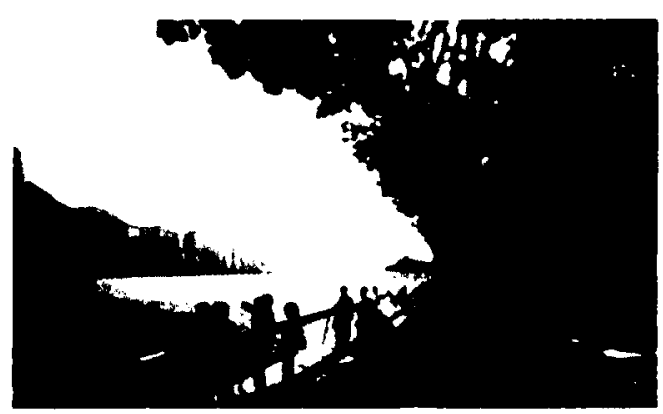

Figure 32 Waterside park, 'Cultural City Park' Master Plan by Sir Norman Foster

\footnotetext{
${ }^{37}$ West Kowloon Cultural District Authority. "Background of WKCD". <http://www.wkcdauthority.hk/en/background of wkcd/index.html>
} 


\subsection{Project}

3.1 Site

T:

he 50 acre site of the terminal is located in the center of the West Kowloon District. It is

bound to the north by a road with heavy traffic (Canton Road), and to the south by the

West Kowloon Cultural District. The site is also located between two major MTR stations: Kowloon Station to west and Austin Station to the east. Integrated into the Kowloon Station is a luxurious residential and commercial complex which adopts the standard raised podium strategy.

There will be three pedestrian access points to the site: the first is from the West Kowloon Cultural District to the south; the second is from the two underground subway stations to the east and west; the third major access point is from the elevated podium mall also to the east. Vehicular access is provided by a road running from east to west through the middle of the site (figure 33). 


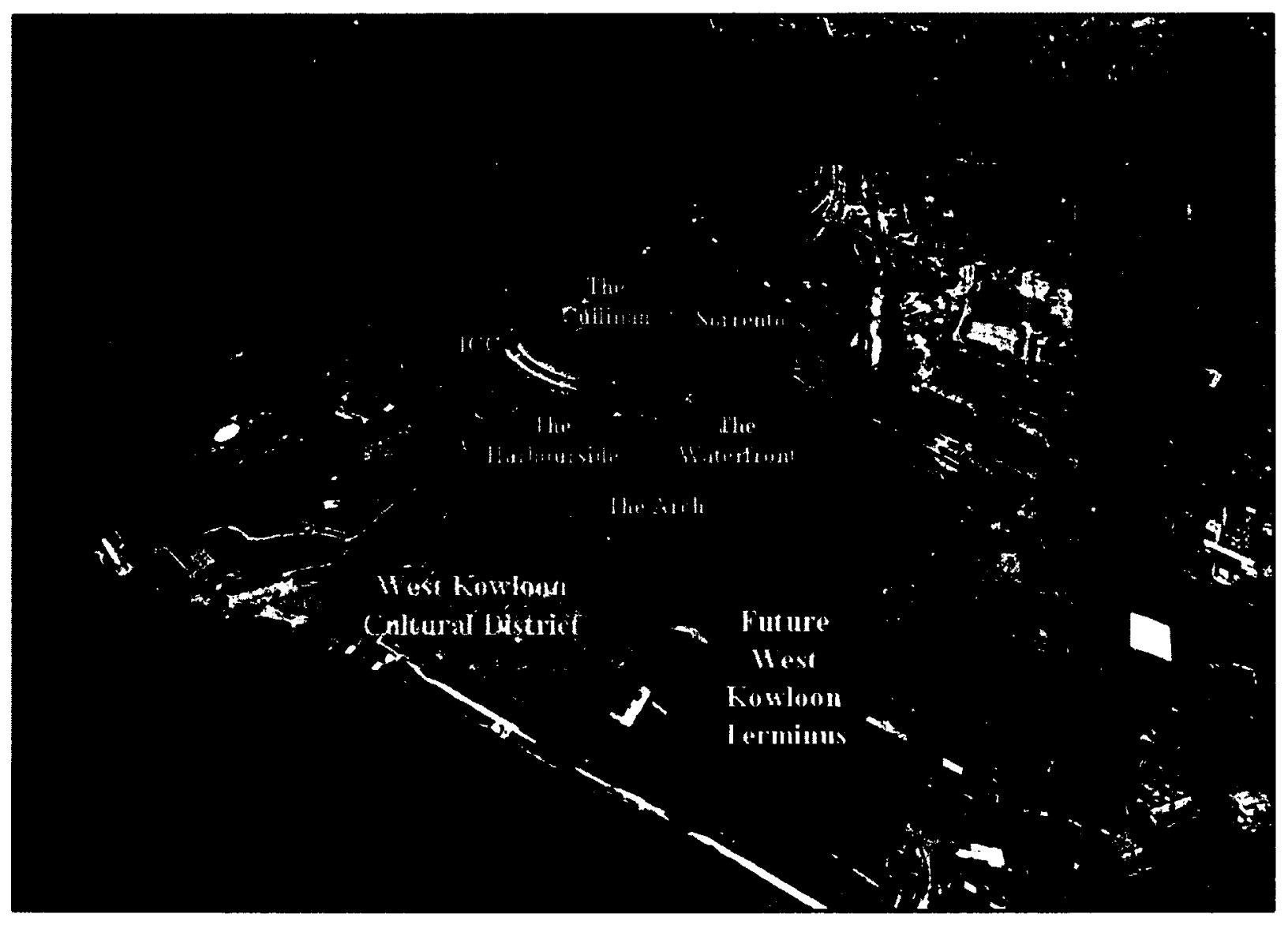

Figure 33 Hong Kong Guangzhou-Shenzhen Express Rail Lind Terminus 


\subsection{Strategy}

\subsubsection{Connectivity}

The multi-layered conditions of the West Kowloon site calls for a unique design strategy that differs from the generic stacked podium approach in Hong Kong. While it is vital to establish above and below ground connections with the existing infrastructure, the ground plane simply cannot be dismissed due to the adjacency of the Cultural City Park. The shape and form of this building should then cater to the vast influx of inter-level pedestrian traffic by facilitating the transitions between floors. (figure 34-35) 



\subsubsection{Programming}

In a brief provided by the Board of the West Kowloon Cultural District Authority (WKCDA), the design intention for the new terminals was stated as follows:

'The overall design vision of the new terminus is to "create a vibrant, low carbon emission, and accessible environment which allows a wide spectrum of uses and activities to be taking place at the same time. While the West Kowloon Terminus (WKT) should enjoy a unique and distinctive identity to signify itself as the southern gateway to the Mainland, its design should be subdued and neutral so that it would be able to blend in well with the adjacent developments, especially the West Kowloon Cultural District (WKCD). ${ }^{38}$

It is clear that a train terminal is merely one of many components of this facility. In addition to all the compulsory programs of an intermodal transport hub - namely the train station, bus terminal and a subway transfer zone - this design proposal also includes a shopping center, a park, a sports complex and a library (figure 36).
WKCDA is a Government appointed board of directors in charge of the artistic developments of the West Kowloon Cultural District.

\footnotetext{
38 "West Kowloon Terminus of the Guangzhou-Shenzhen-Hong Kong Express Rail Link-Briefing by Railway Developed Office, Highway development office, Highways deparapment." Nard of the Wet Kowloon Cultural District Authority. 26 November 2009.
} 


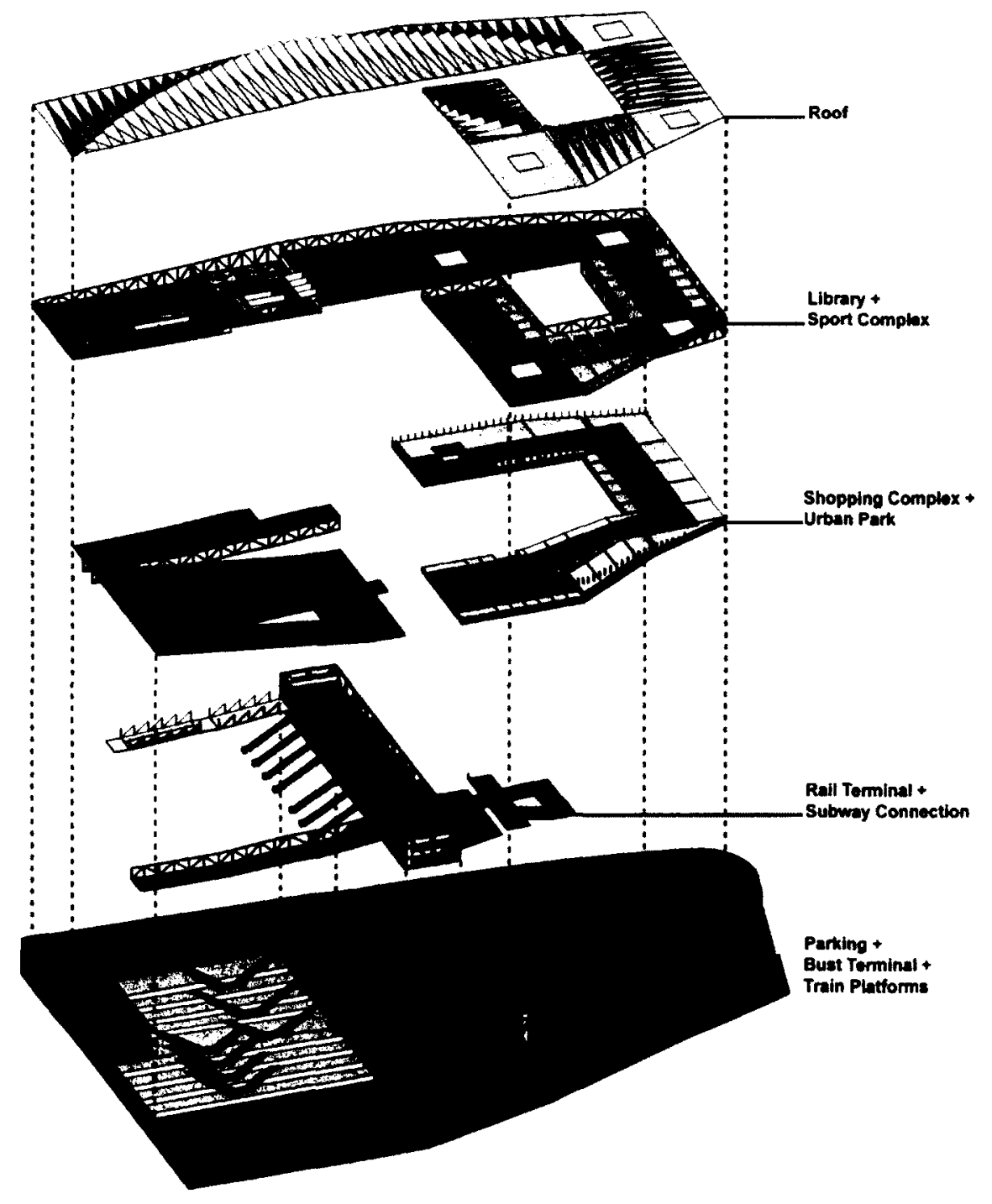

Shopping Centers

Commercial programs have long been used in the transport hub typology due to the large volumes of traffic.

\section{Park and Sporting Facilities}

Public green spaces are a rare commodity in Hong Kong. Due to the hyper dense situation of Hong Kong, the current supply of green spaces which includes parks and recreational facilities in Hong Kong are grossly inadequate to sustain present population. According to the guidelines provided in the Metro Plan published in September $1991^{1}$, the current provision of 8 hectares of open space in Kowloon needs to be supplemented by an additional 19 hectares to meet regulations.

Library

The library typology had undergone a transformation of its own. In addition to merely being storage for book stacks and quiet study areas, many modern libraries such as the Seattle Central Library, designed by Rem Koolhaas, contains spaces that encourage group work and social interactions. The only public library available near the West Kowloon region is inadequate in size and located in an area not immediately accessible by a MTR station. The inclusion of a large scale library on the train terminal site would be an invaluable addition to both the social and informational dimension of the surrounding region.

Figure 36 Exploded Axonometric 


\subsection{Components}

The building can be broken down in to three main components; the urban park, the intermodal transport hub and the train shed.

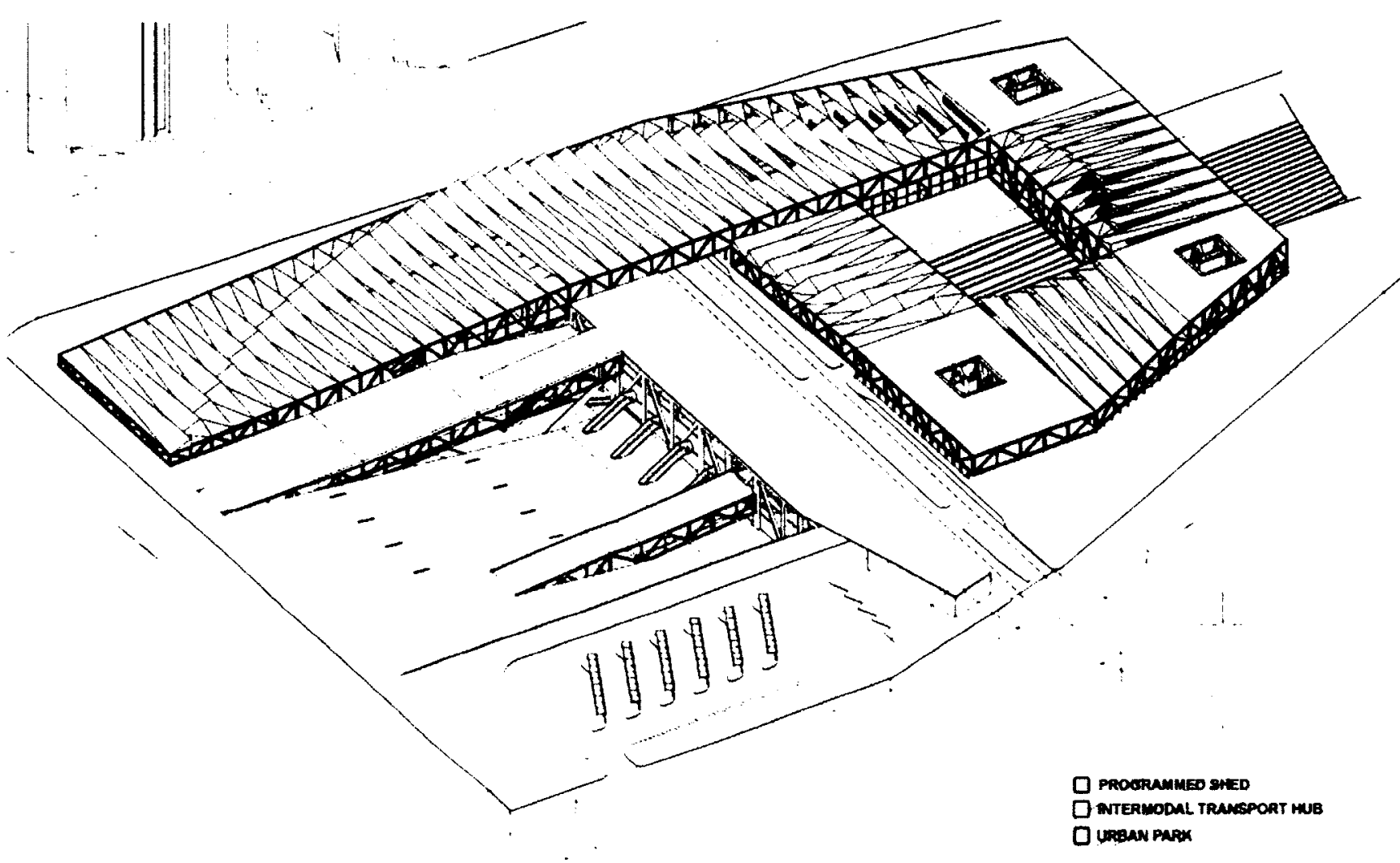

Figure 37 Overall Components Breakdown 


\subsubsection{Intermodal Transport Hub}

This facility houses 4 modes of transportation systems: Intra-city rail terminal, a local subterranean rail connection (MTR), a bus terminal and vehicular access. The transport circulation study by Brian Richards (refer to section 1.4) exerted the use of a continuous pedestrian belt as an organizing element of a transport hub; because the West Kowloon Terminal site is sandwiched between two major MTR stations (Kowloon Station and Austin Station), such a 'pedestrian belt' can be created in the form of an underground tunnel connection between these stations. The two-story intra-city rail terminal station - consisting of a main ticketing hall and arrival halls - is then placed directly on top of this underground connection. The head station typology (refer to section 1.2) is adopted by positioning this long rectangular building perpendicularly across the train podiums. Not only does this approach free up the entire site for the railway tracks, the head building (which is encapsulated by a mega truss) can be used a core structural element for the extensive train shed overhead(figure 38). The existing road running from the east end of the site to the west end is retained as an access point for both public and private vehicular traffic. The local bus terminal is placed on the east end of the site providing easy above ground pedestrian access to both the urban park and Austin Station. 


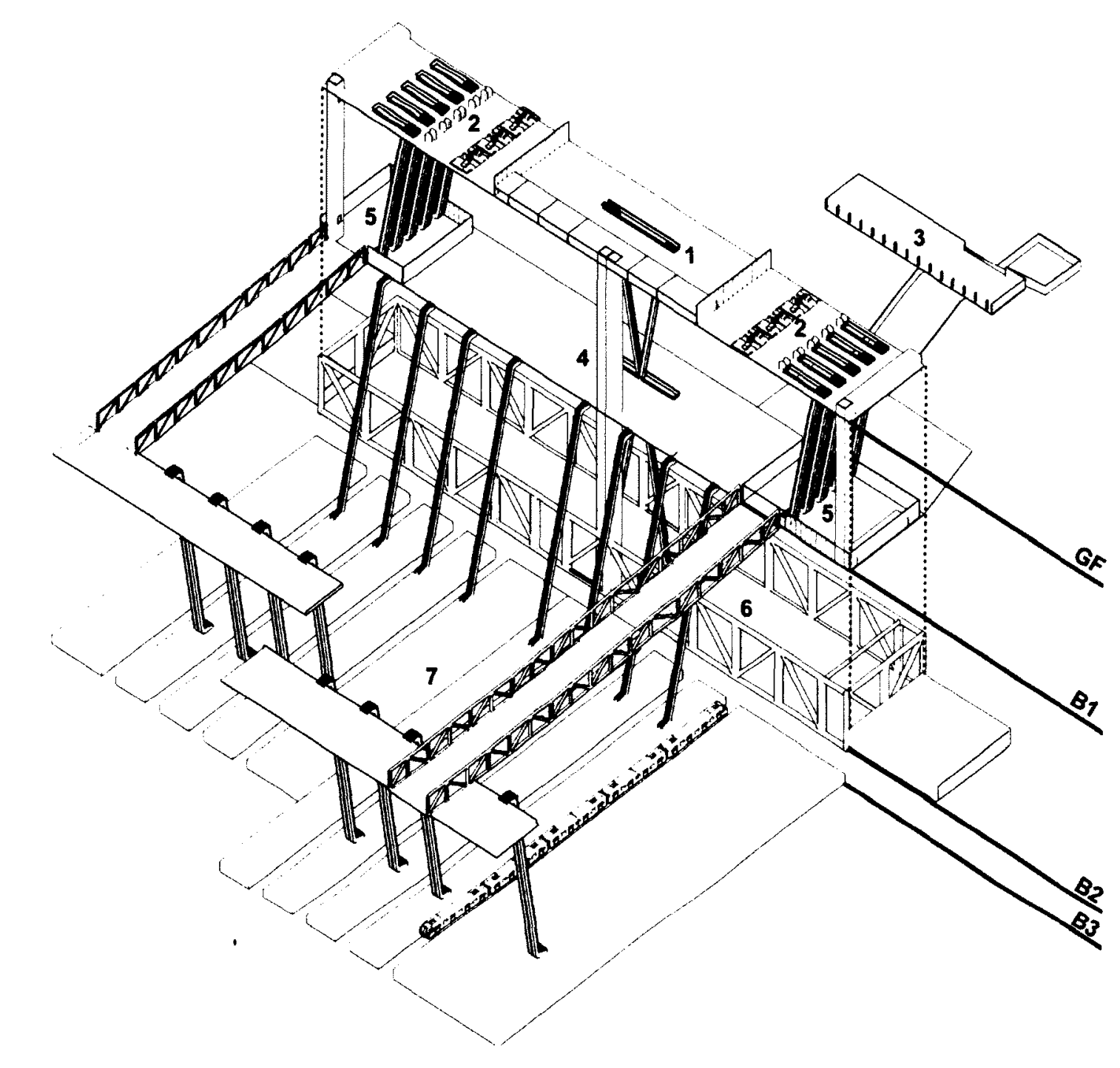

1. Main Entrance and Ticketing Hall

2. Departure Security Check point and immigration.

3. Arrival Hall

4. Arrival Immigration and Security Check Points

5. Departure Halls and Lounges.

6. 'Pedestrian Moving Belt' between

Kowloon Station and Austin Station.

7. Train Platforms.

Figure 38 Exploded Axonometric of the "Head Building" 
3.3.2 'Programmed Train Shed'

A massive train shed of nearly 300 meters spans almost the entire length of the site. This shed differs from the great trains sheds of the past, however, in that aside from merely functioning as an shelter for the rail terminal, it also contains additional programmatic functions. These nontransport related programs not only serve as waiting areas for passengers, but also as activity generators for the surrounding region (figure 39). 


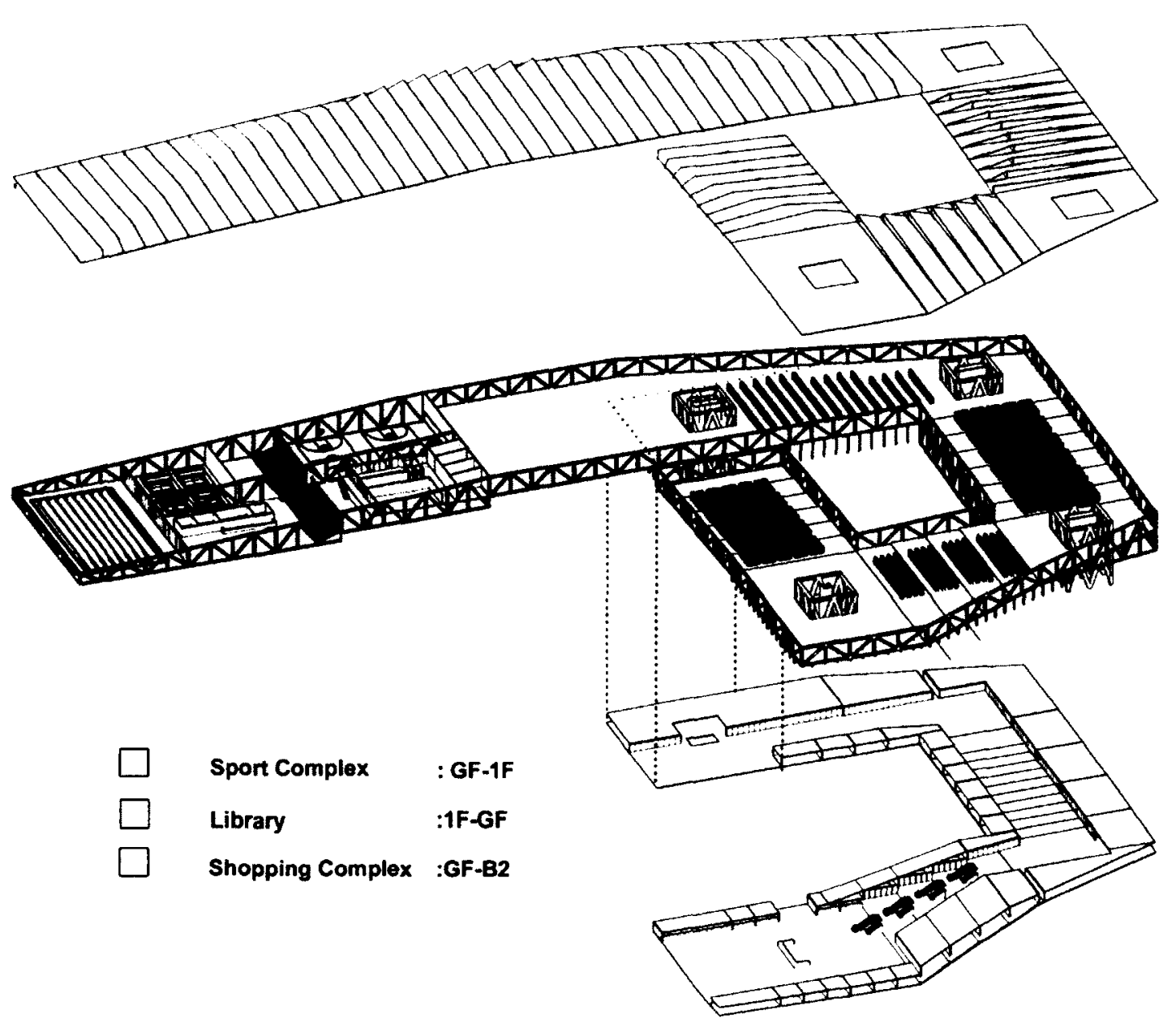

The 'programmed shed' takes the form of continuously loop beginning at ground level on the south side of the site and then ramps up one story to meet the head building at the center of the site. This portion contains a multi function sport complex. At this point, the shed ramps back down in the form of a loop to meet the ground plane. This portion contains the library. It then loops down a second time from this point connecting the ground plane with the underground subway system and urban park. This last portion contains a shopping facility and food court. 


\subsubsection{Urban Park}

A 12000 square meter sloping urban park is placed on the south side of the site directly across

from Norman Foster's Cultural City Park, providing pedestrian access to the sports complex and

library. This park meets the head building at the underground subway connection level, which is

also connected to the shopping mall (figure 36 ). 


\subsection{Circulation}

A smooth flowing circulation system is vital in a building of such magnitude. While the 'programmed shed' serves a gradual inter-level connector, the appropriate placements of circulatory devices such as elevator and escalators provide quicker and more direct routes between floors. This is particularly important in the railway terminal component. Although the city o Hong Kong is now part of China, Hong Kong citizens are still required to go through immigration when traveling to and from China. For this reason, along with the basic programs of a train station, this building must also include programs such as immigration booths, customs and security checkpoints (figure 40). 


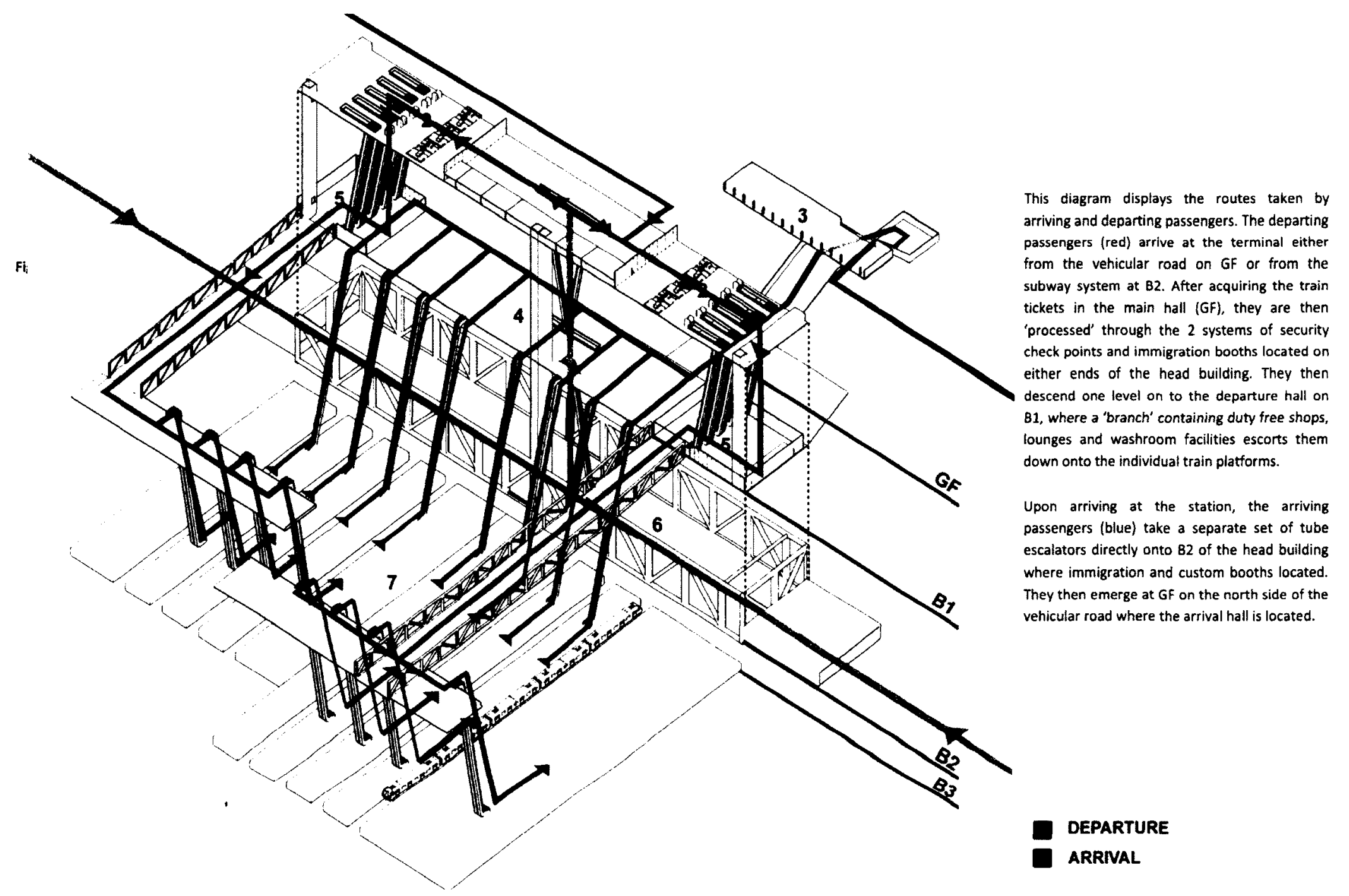




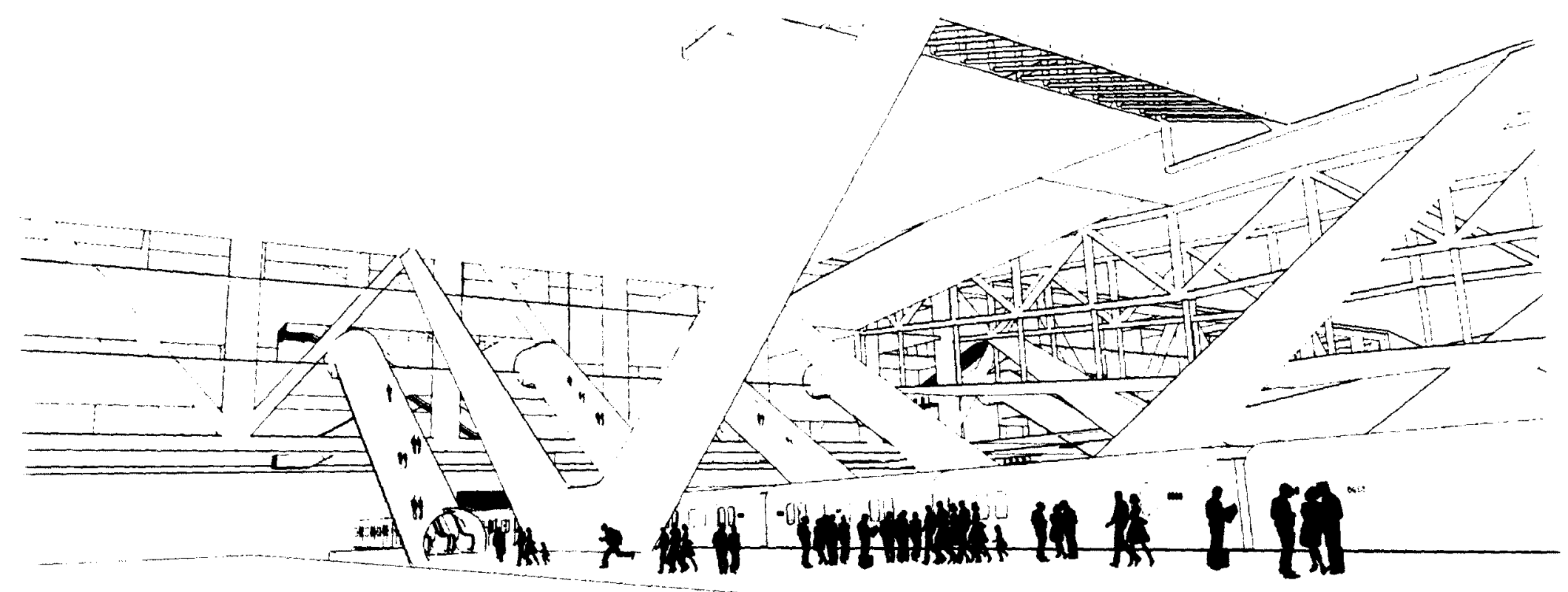

Figure 41a Train Terminal Perspective (B3) 


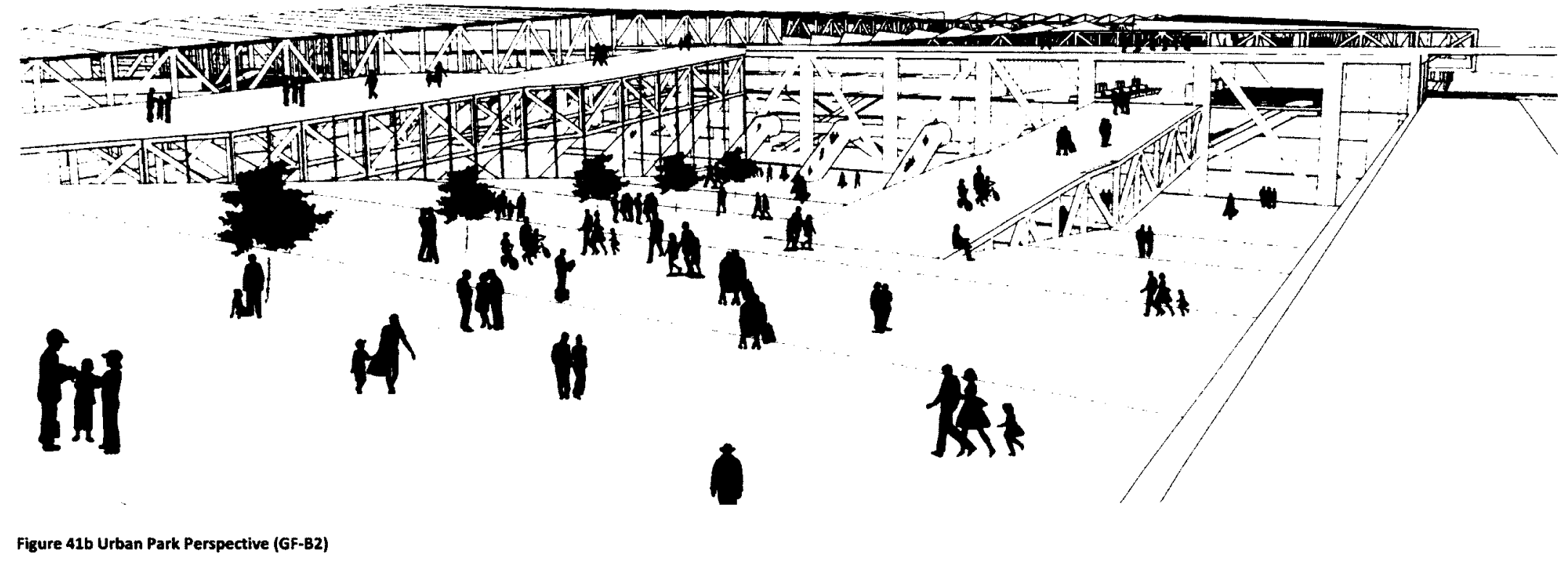




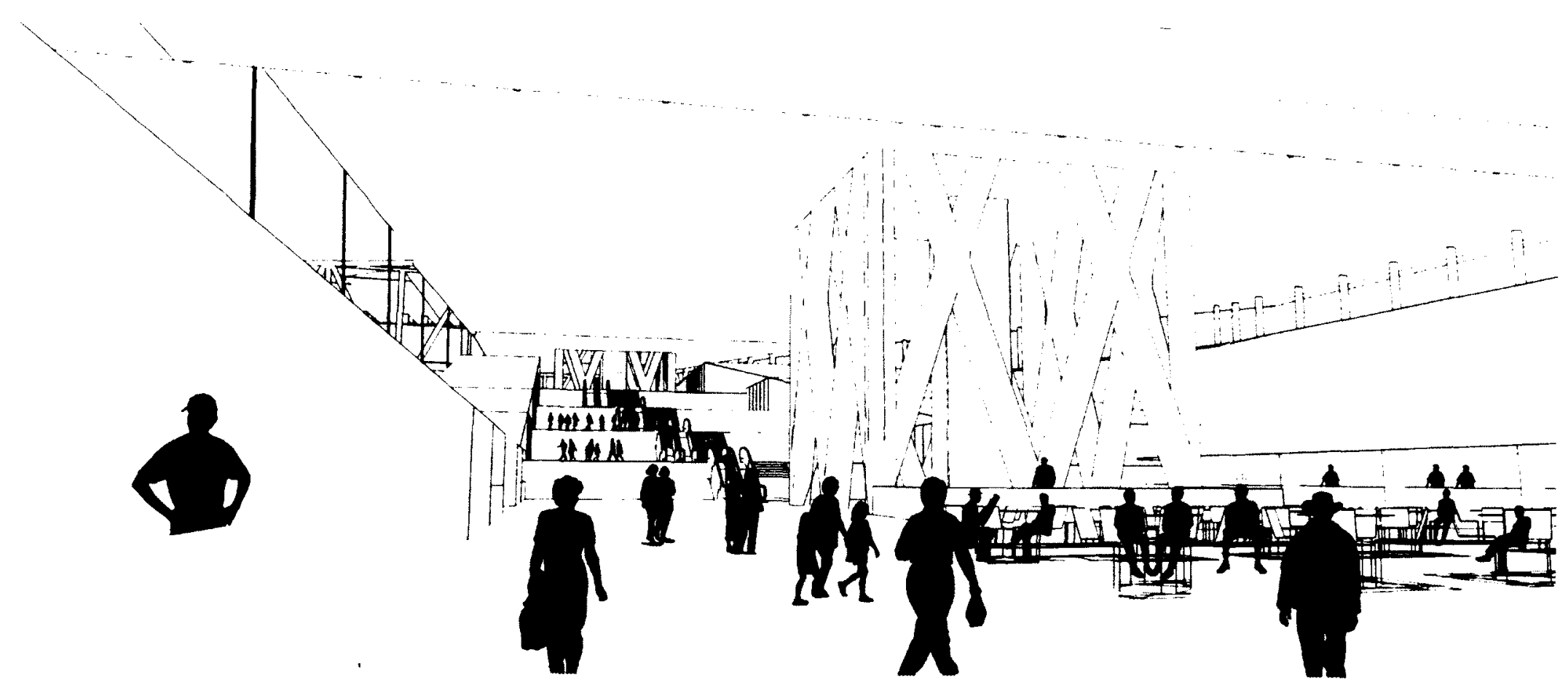

Figure 41C Food Court and Shopping Center Perspective (B2) 


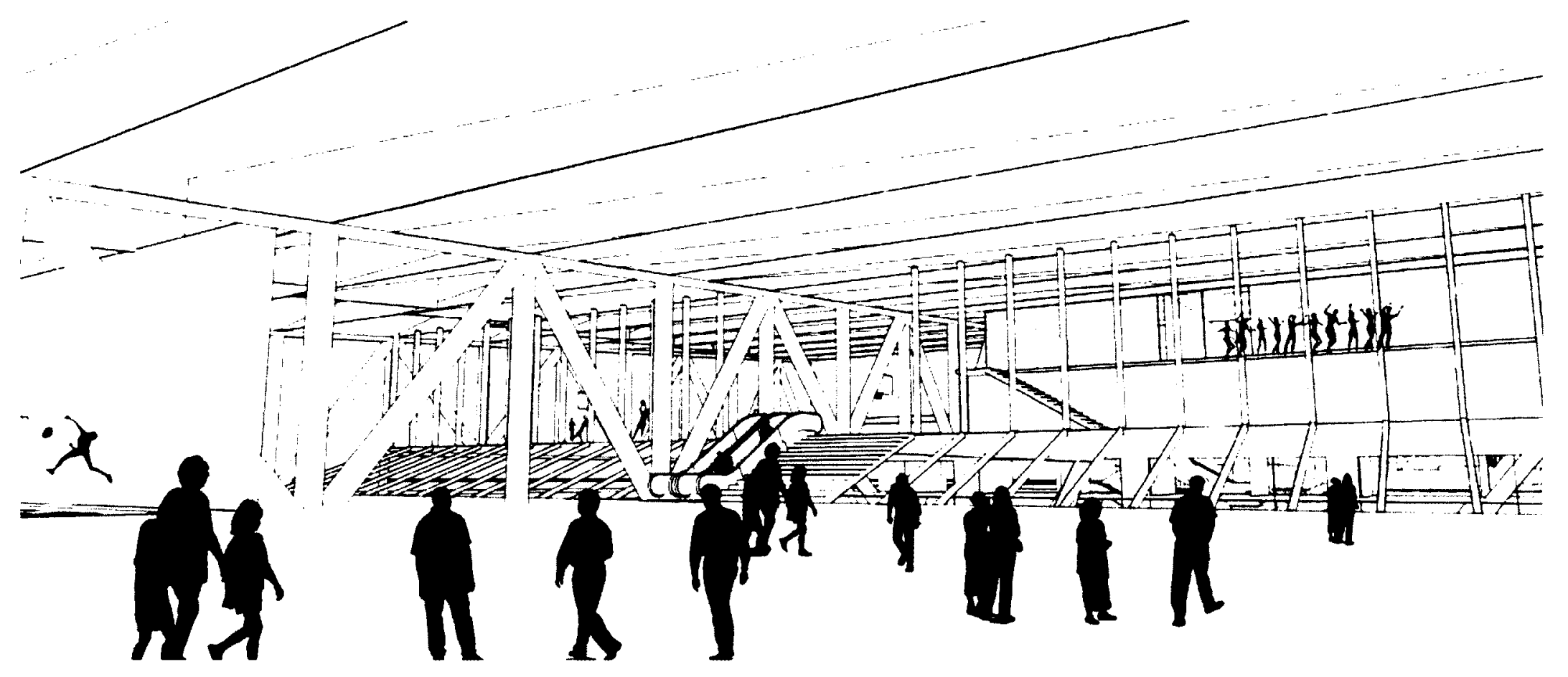

Figure 41d Sports Complex (GF-1F) 


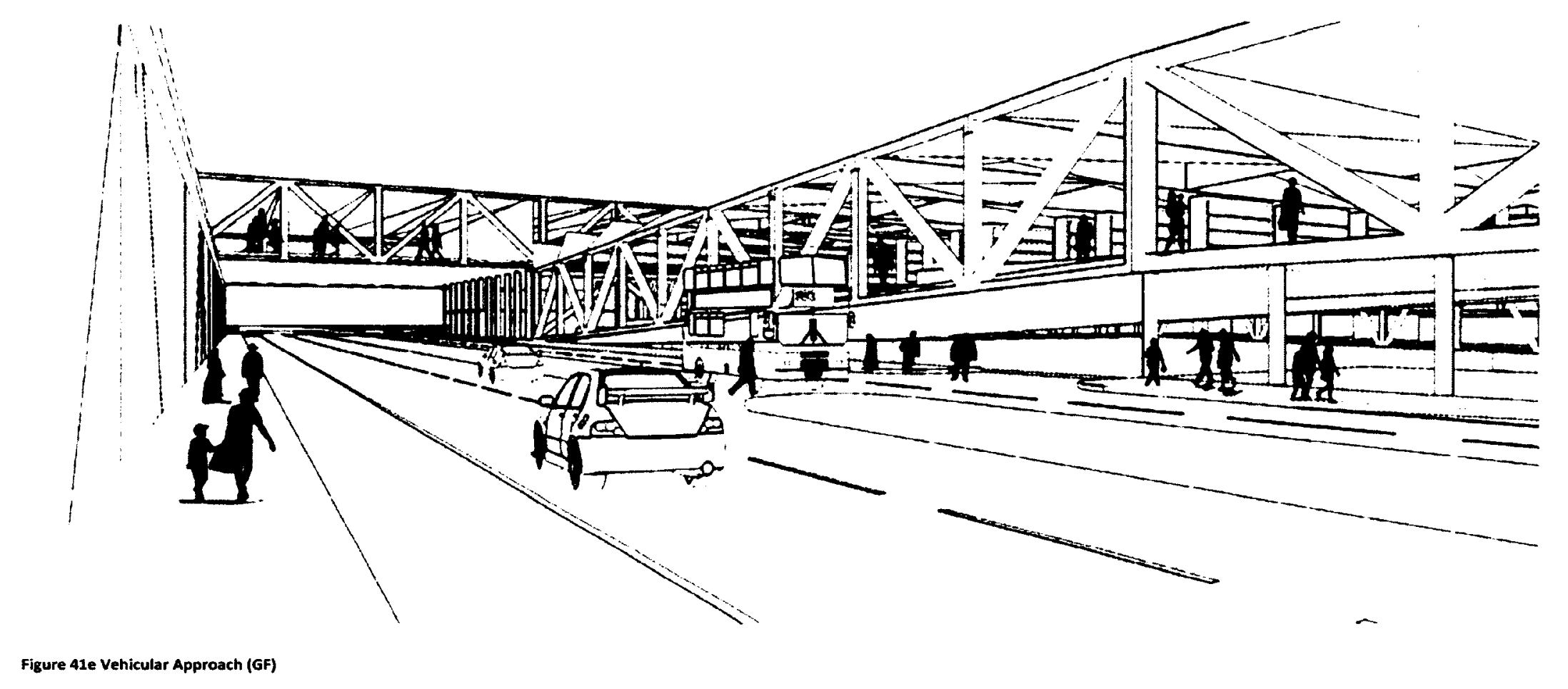




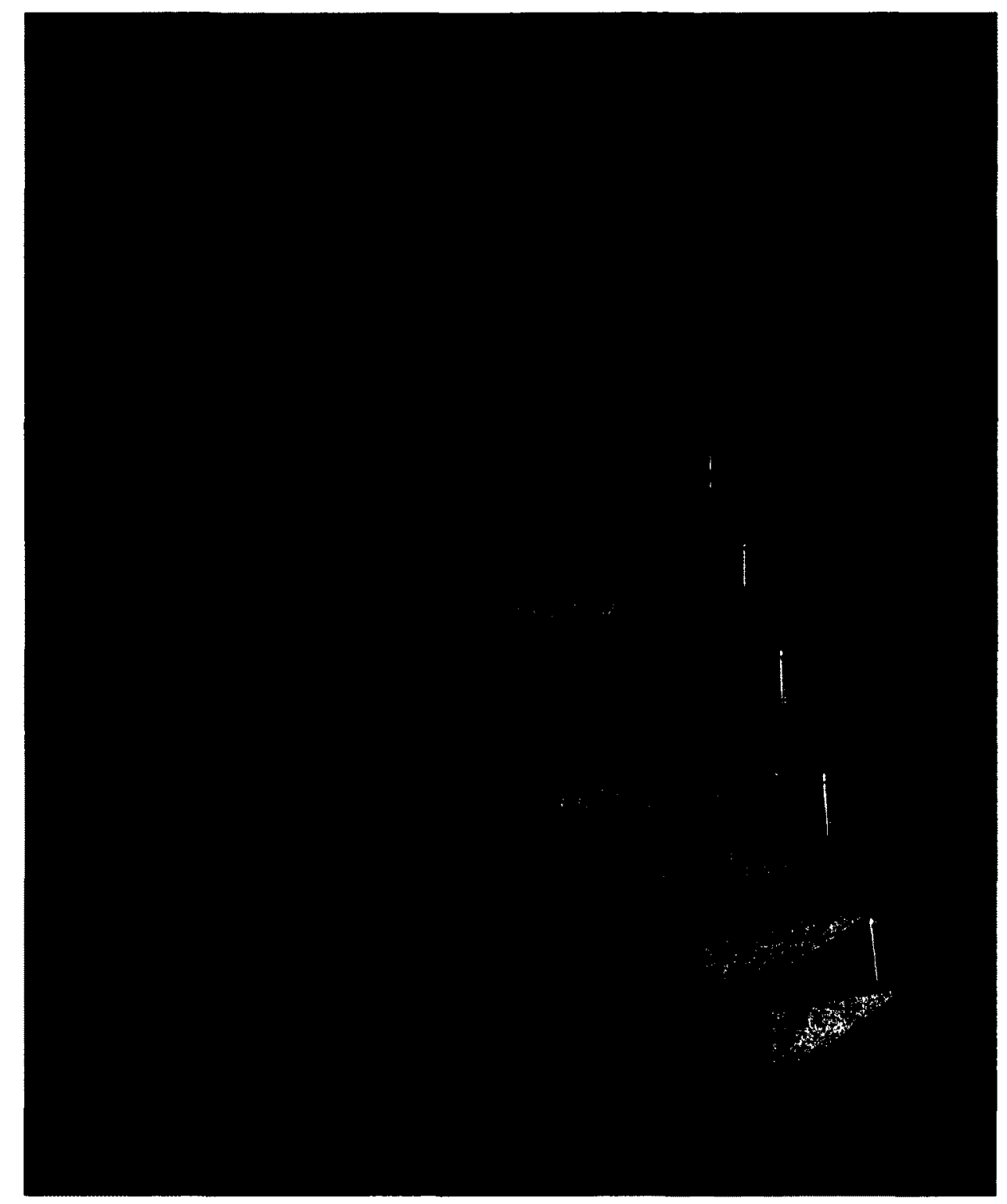

Physical Model Picture 1: Roof Structure over Sports Facility 


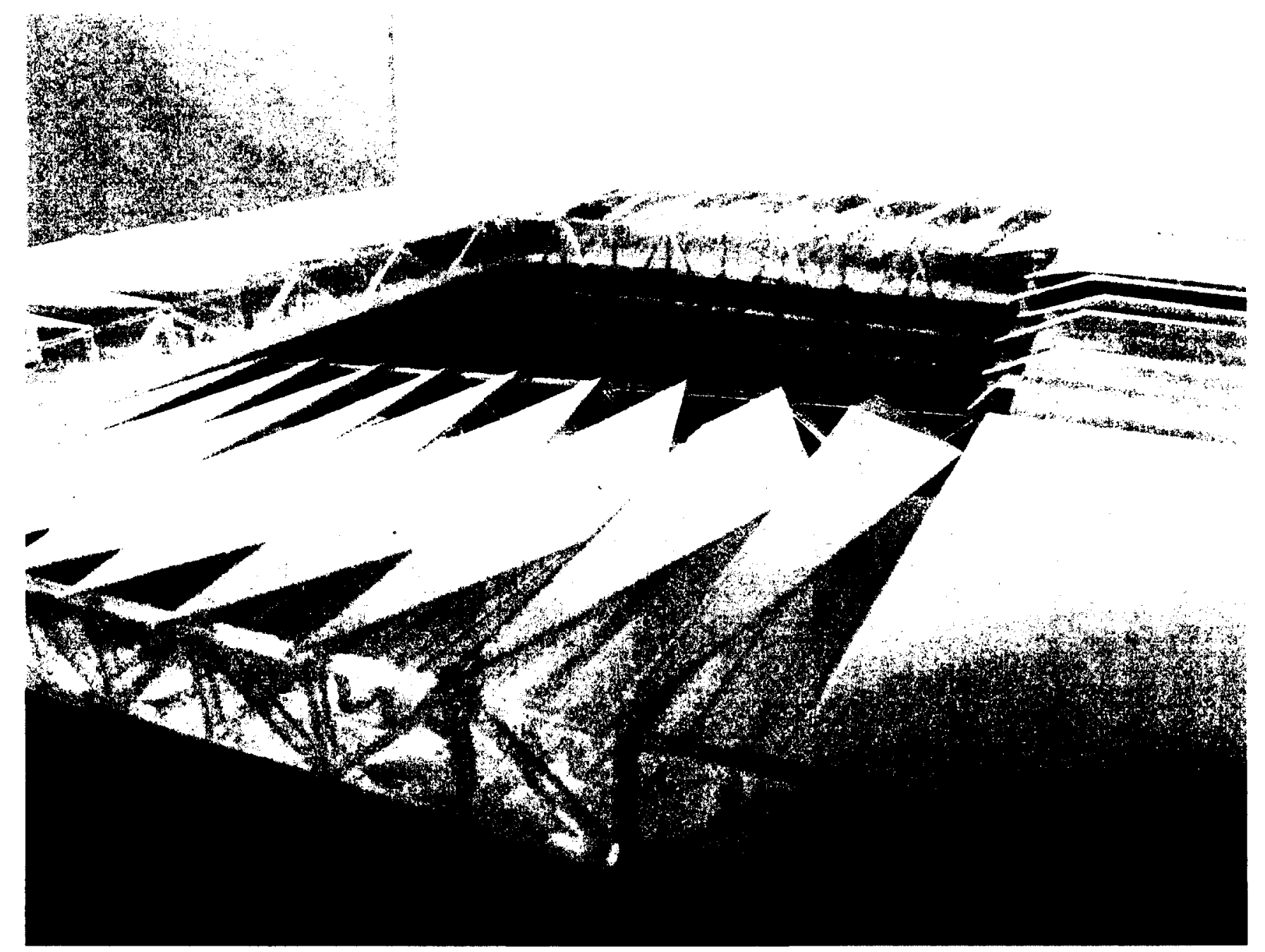

Physical Model Picture 2: Roof over Library and Shopping Complex 


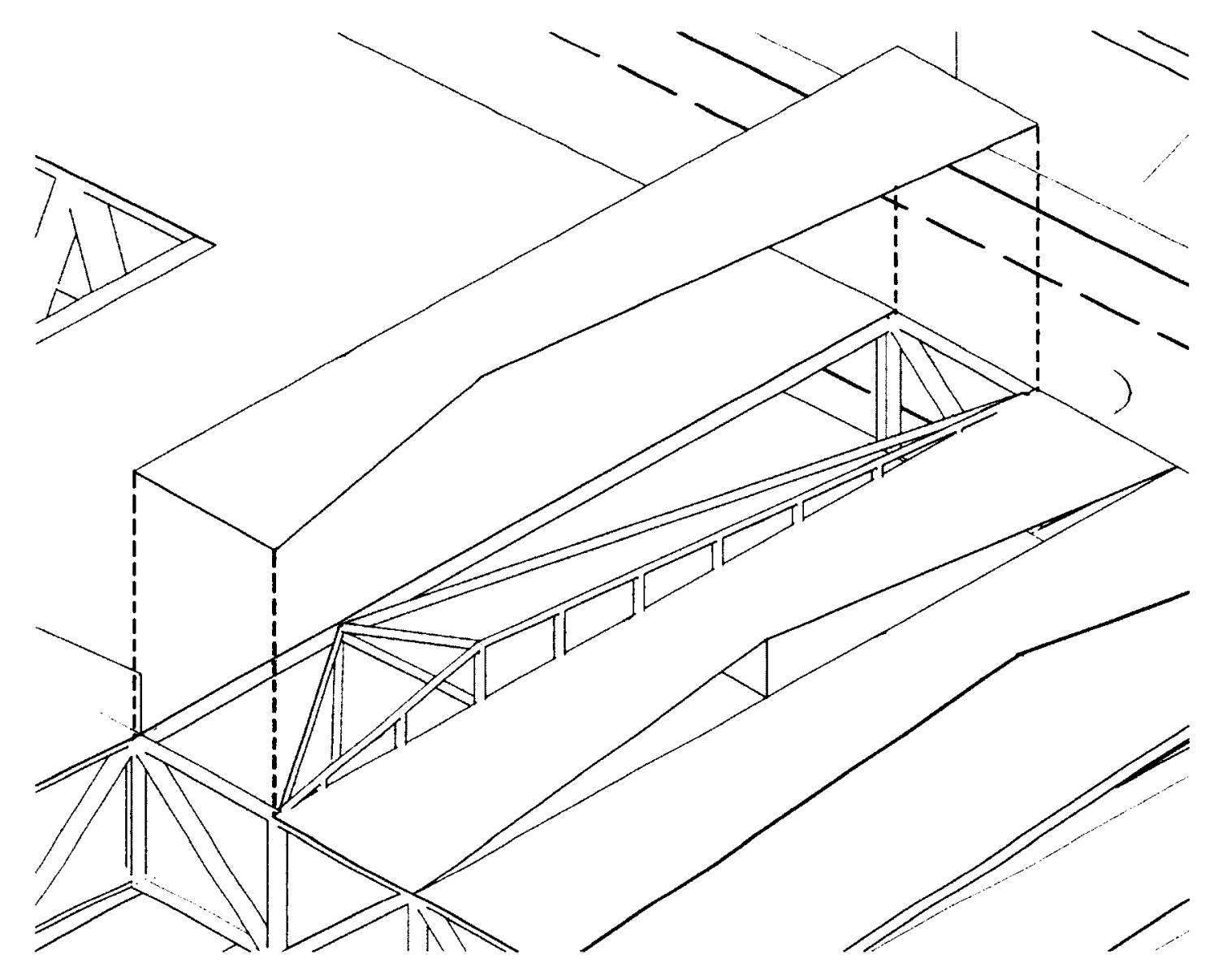

Roof Detail 
3.5 Plans, Sections and Elevations 


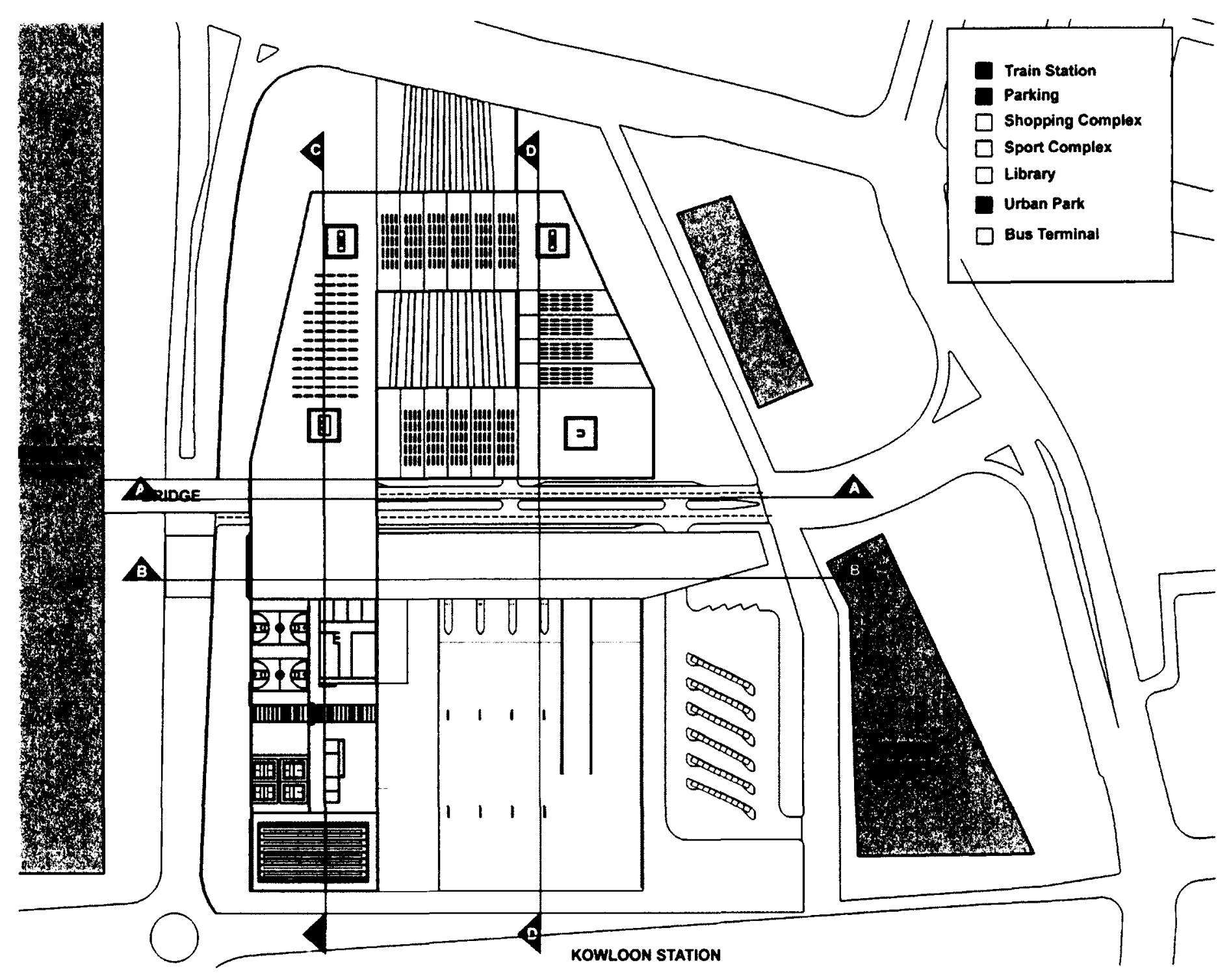

Figure 42 If Plan 


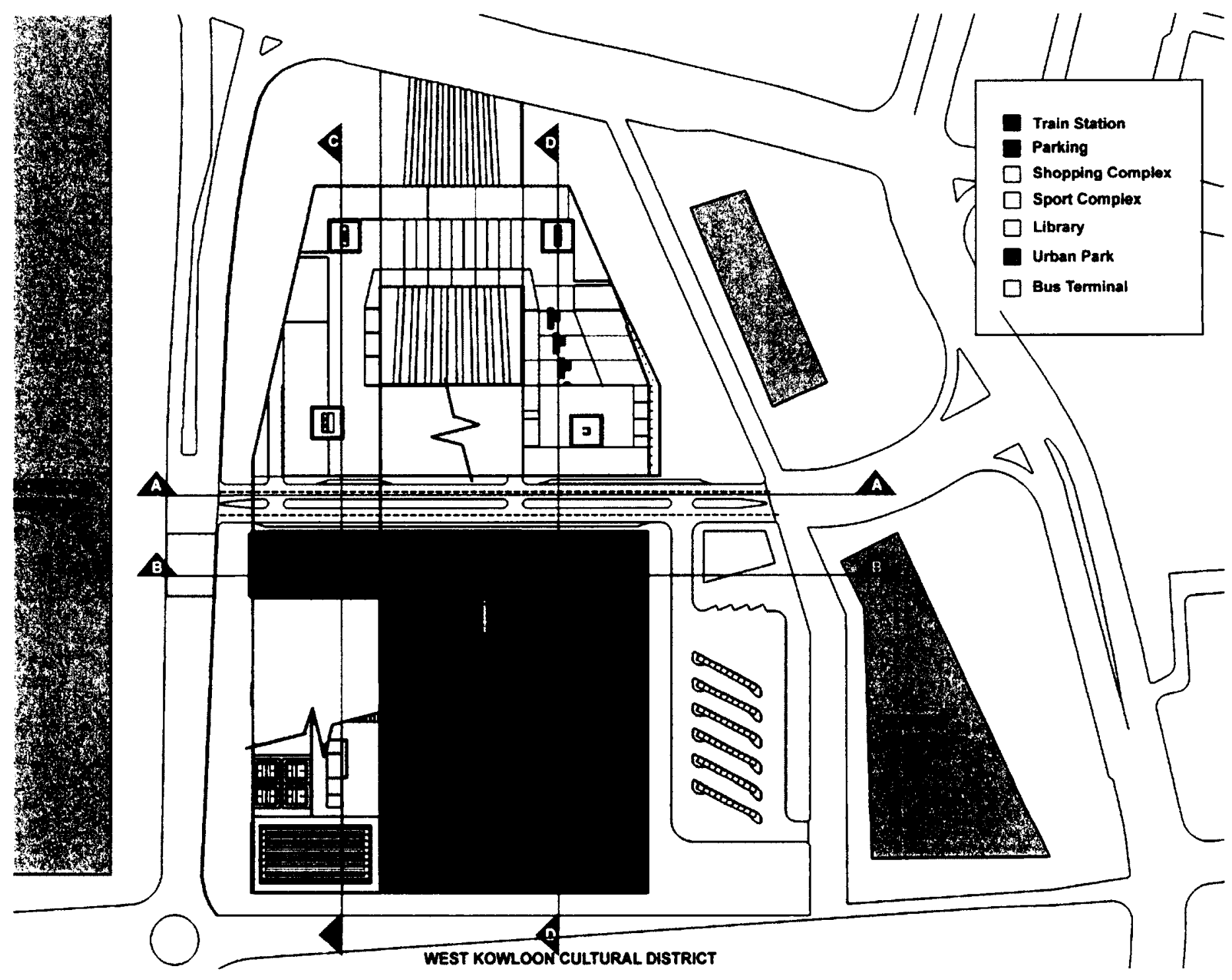

Figure 43 GF Plan 

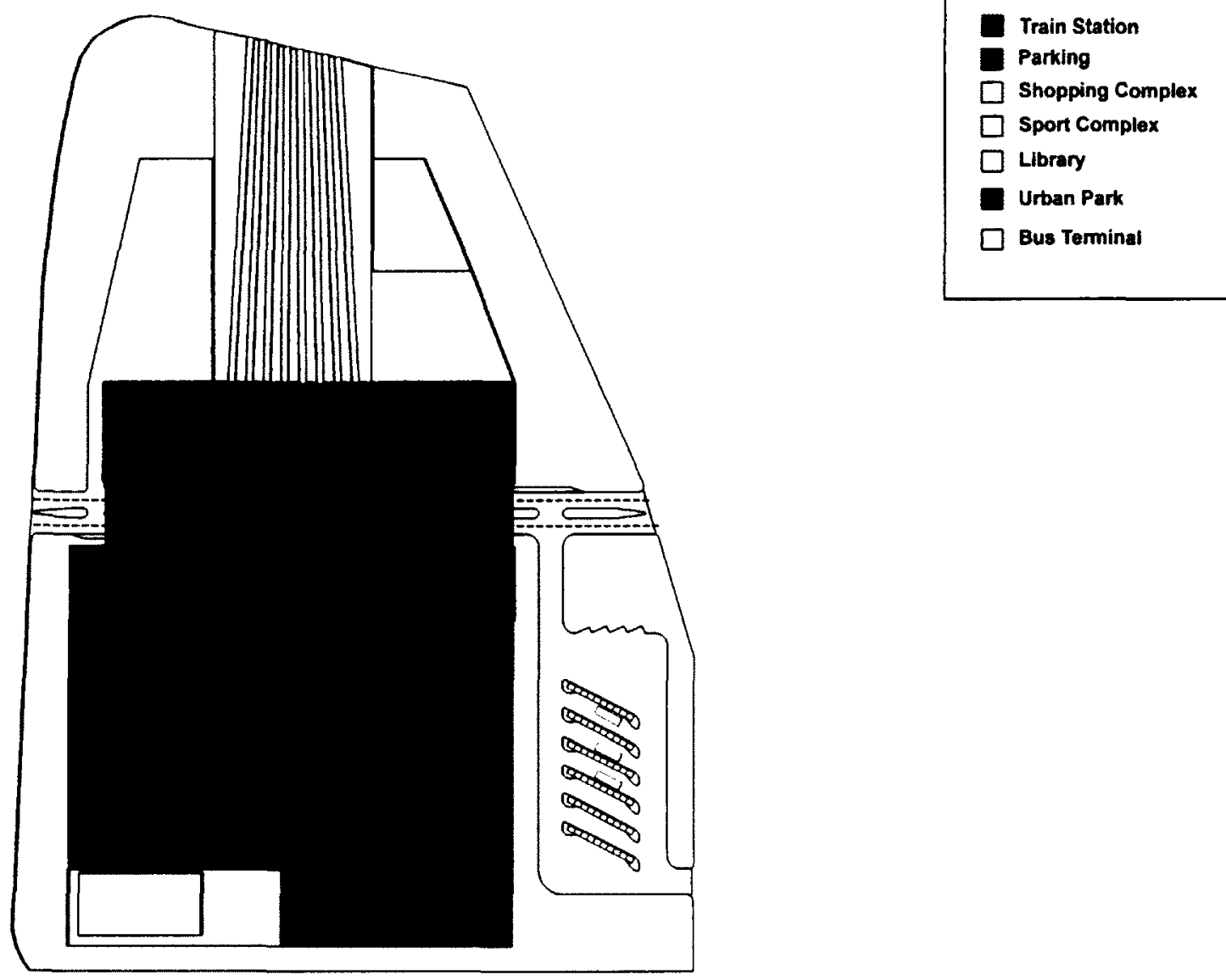

Figure 44 B1 Plan 


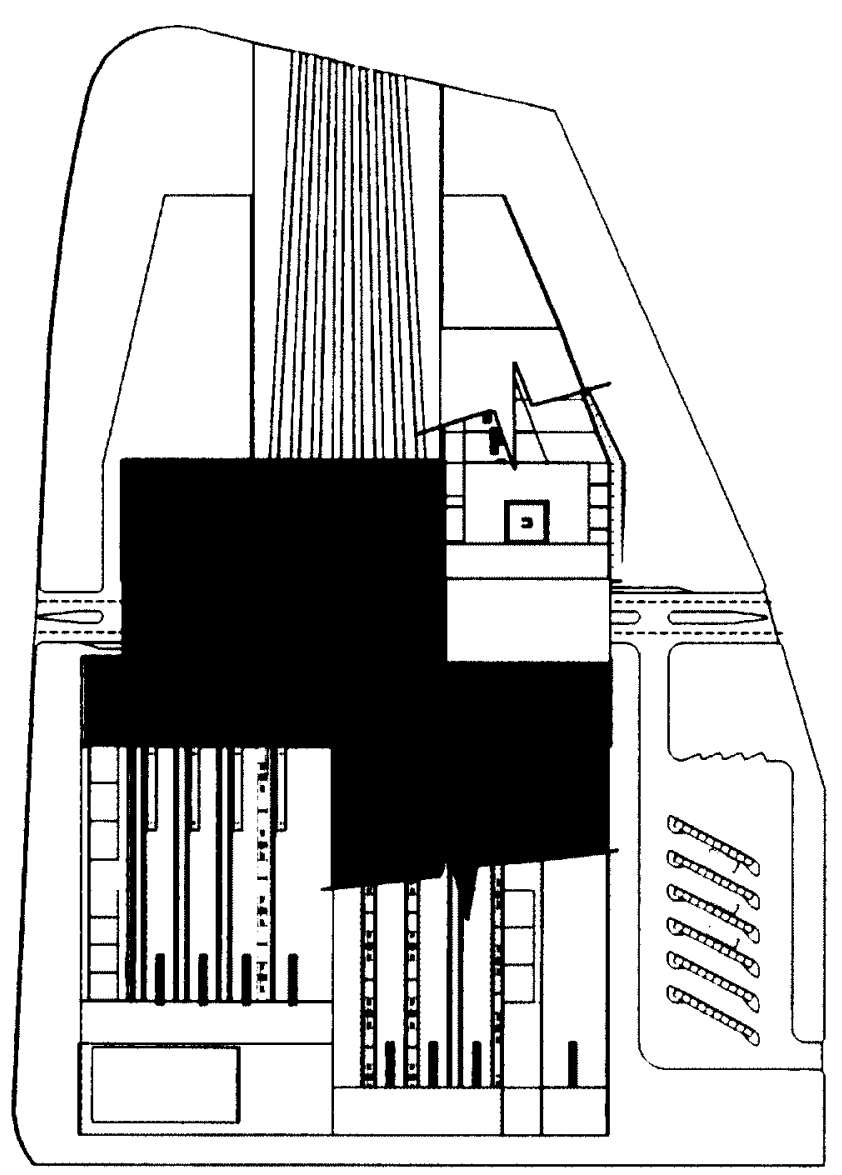

- Train Station

Parking

$\square$ Shopping Complex

$\square$ Sport Complex

$\square$ Library

C Urban Park

$\square$ Bus Terminal

Figure 45 B2 Plan 


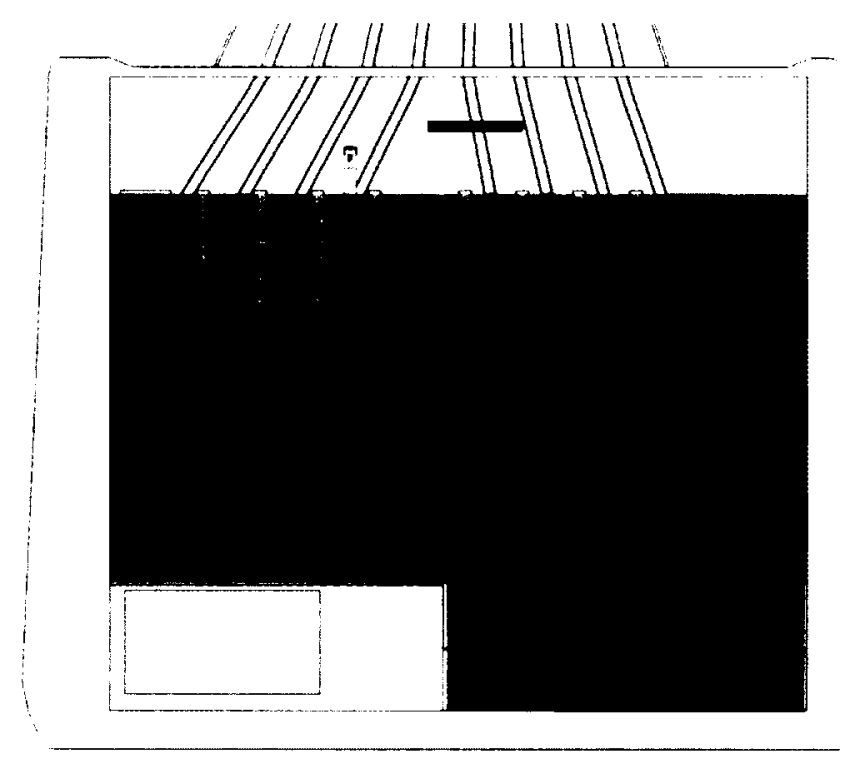

\begin{tabular}{|l|}
\hline \\
Train Station \\
Parking \\
$\square$ Shopping Complex \\
$\square$ Sport Complex \\
$\square$ Library \\
$\square$ Urban Park \\
$\square$ Bus Terminal \\
\hline
\end{tabular}

Figure 4683 Plan 


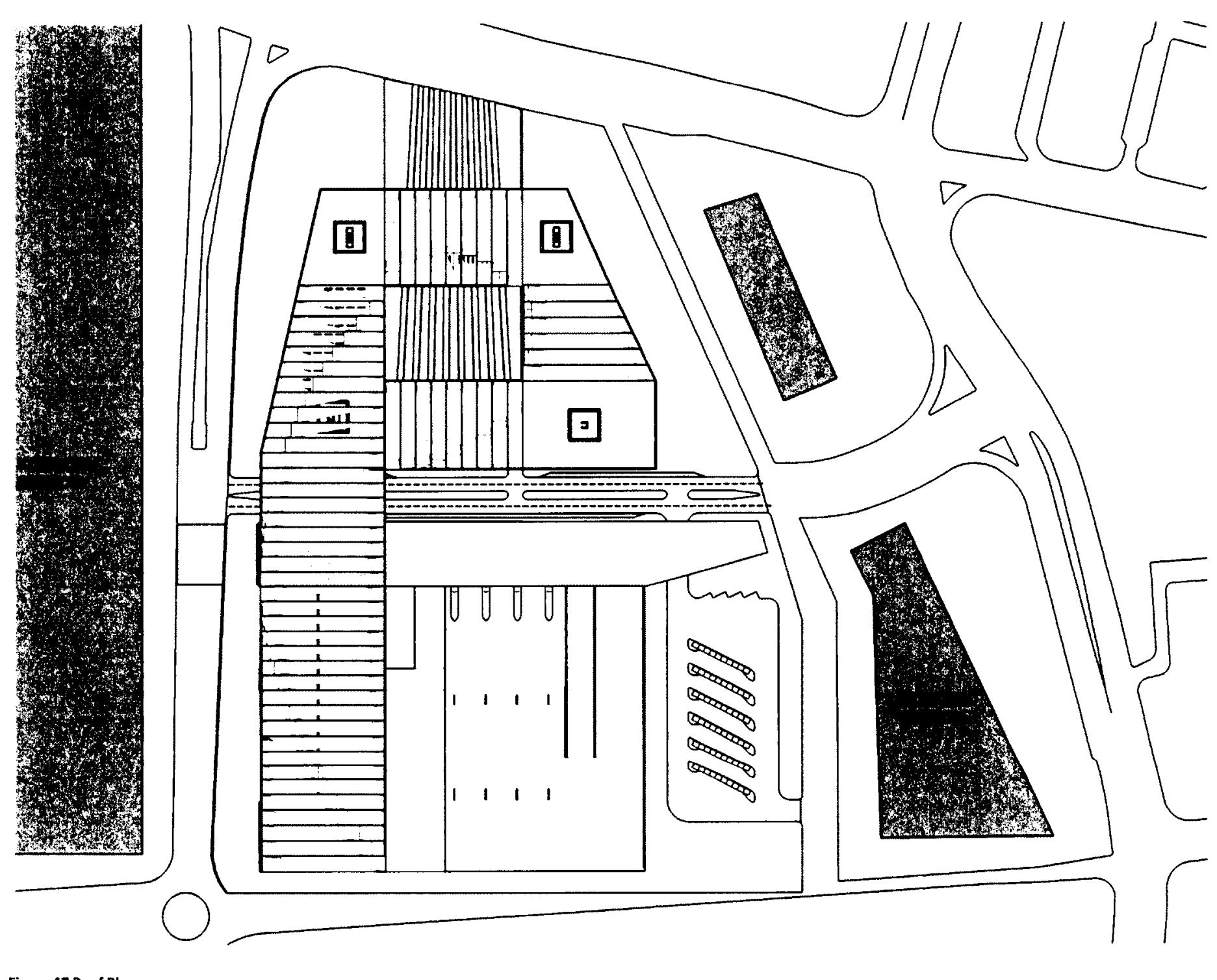


$\Xi \quad$ Pution

$\equiv$ shoppong complex.

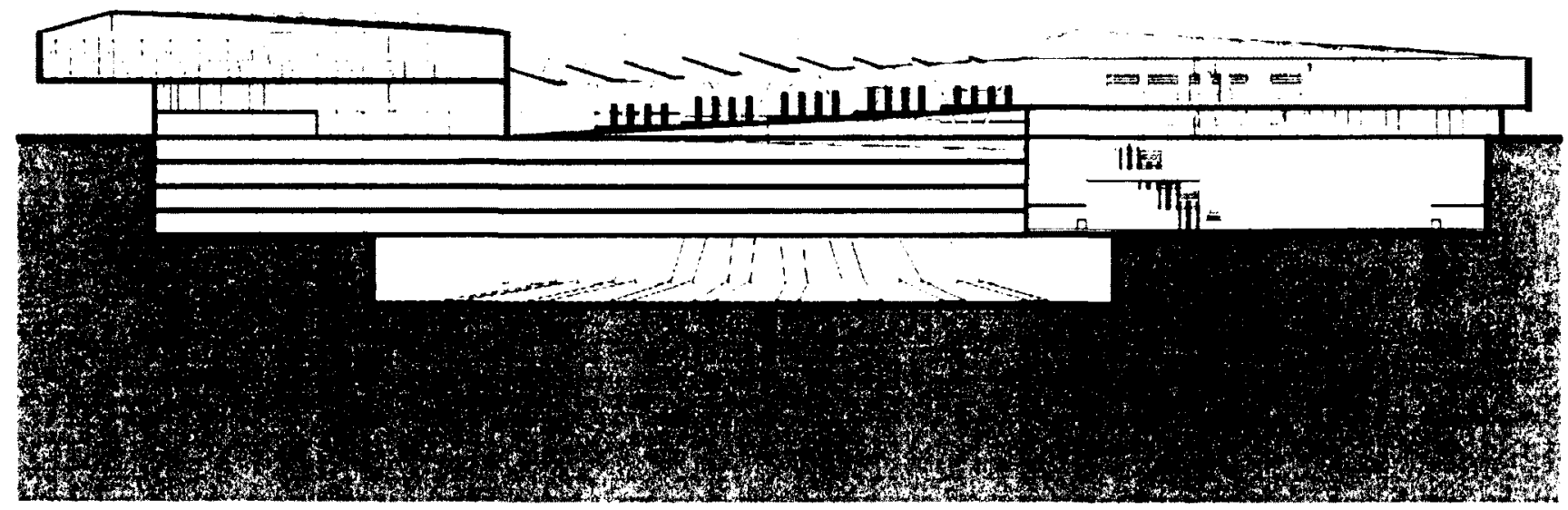

Figure 48 Section A 


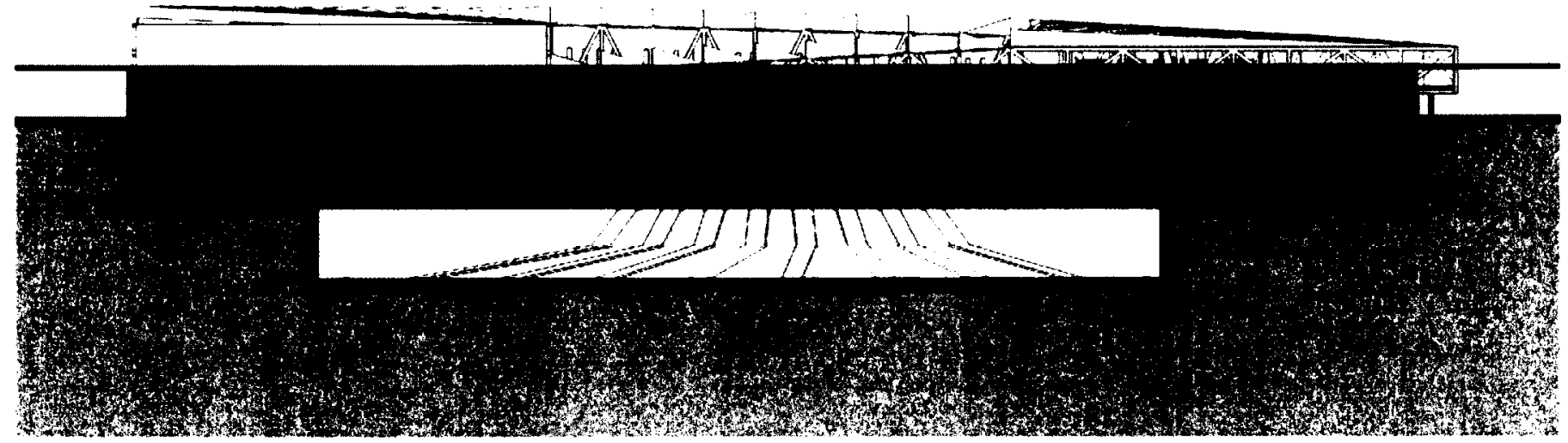

Figure 49 Section B 

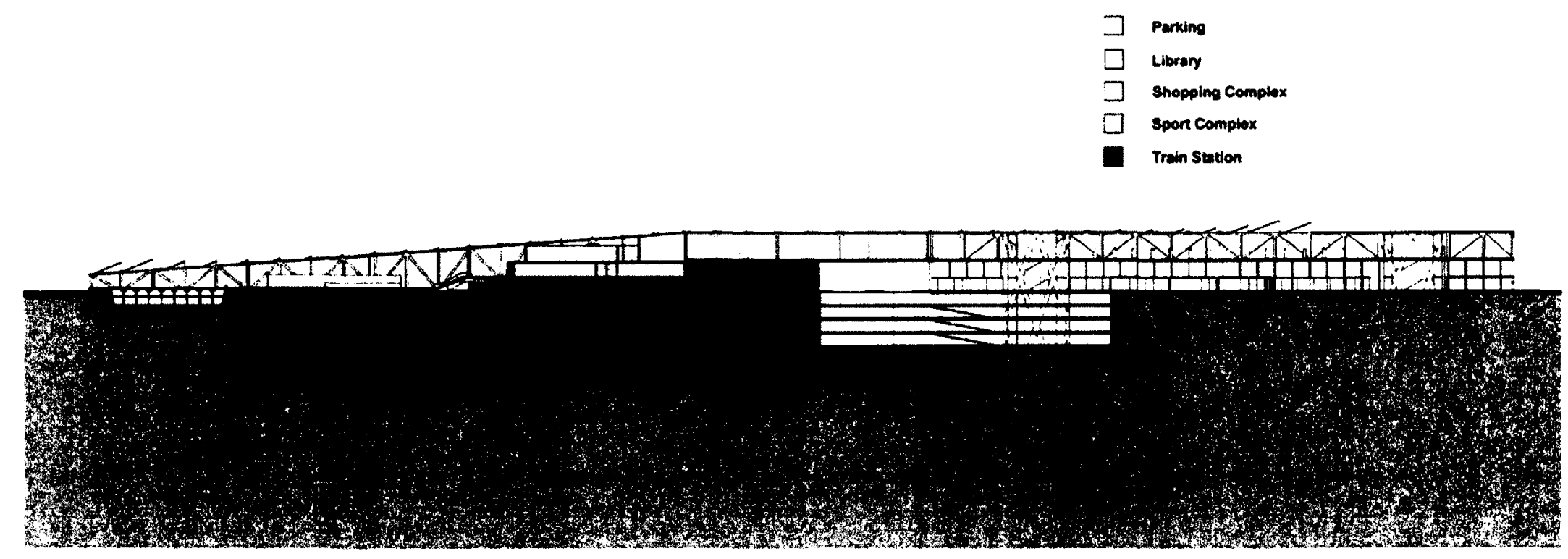

Figure $\mathbf{5 0}$ Section C 

$\square \quad$ Libray
$\square$ shopping Complox
D Train Station

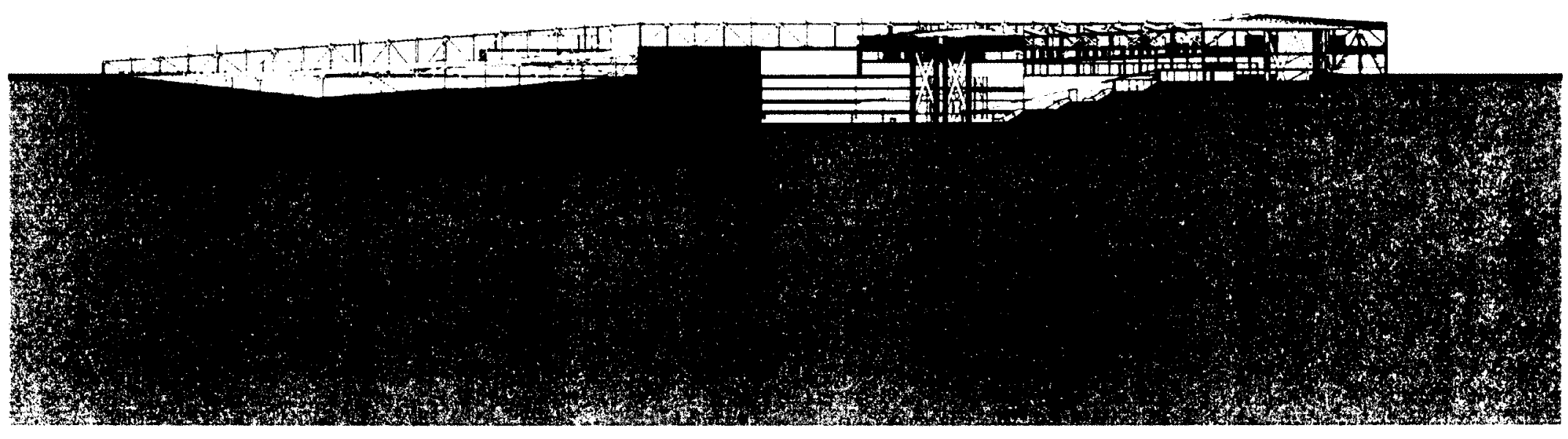

Figure 51 Section D 


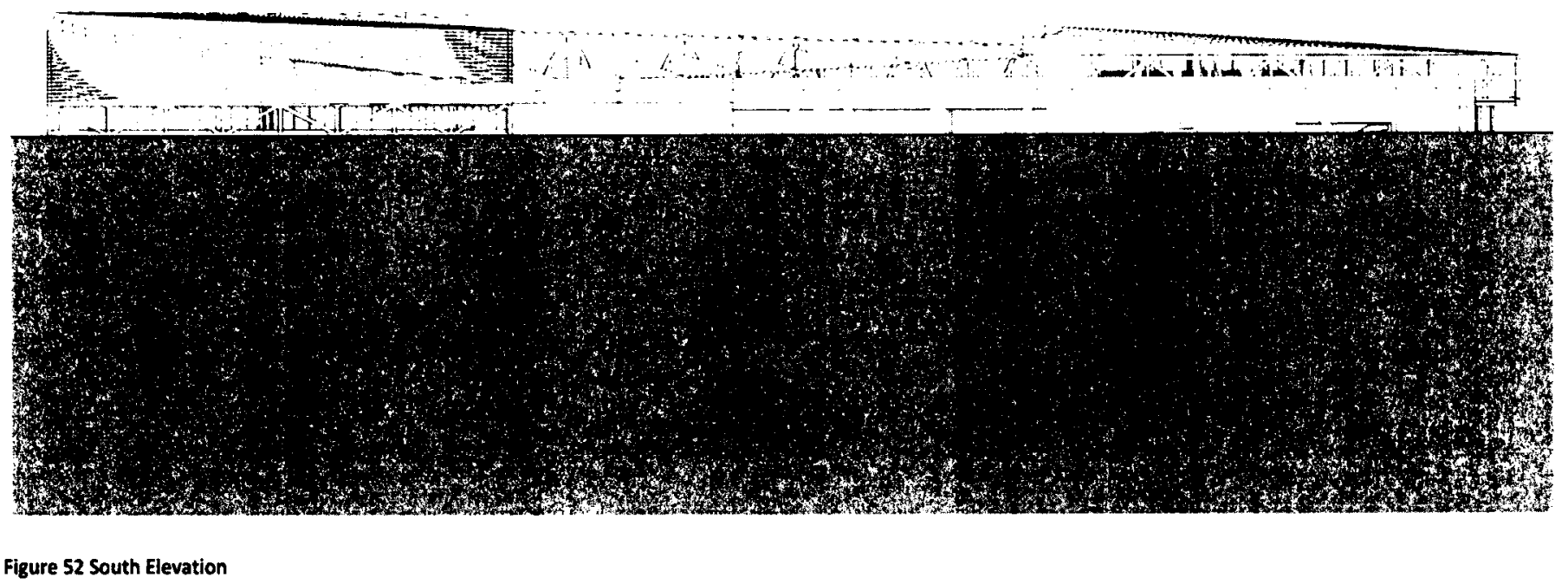




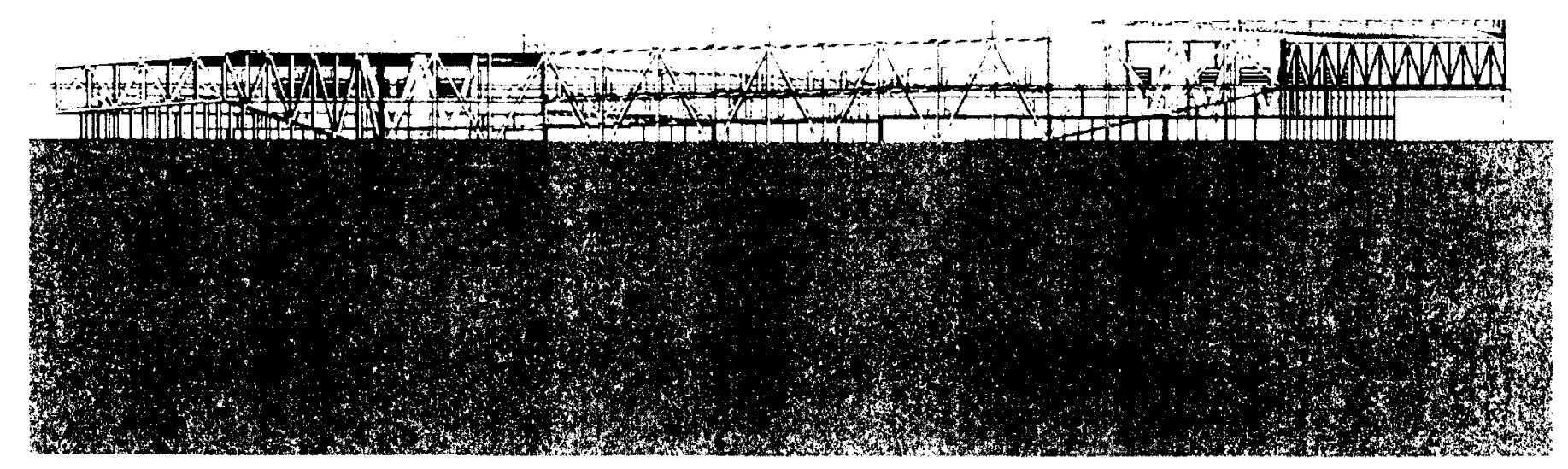

Figure $\mathbf{5 3}$ North Elevation 


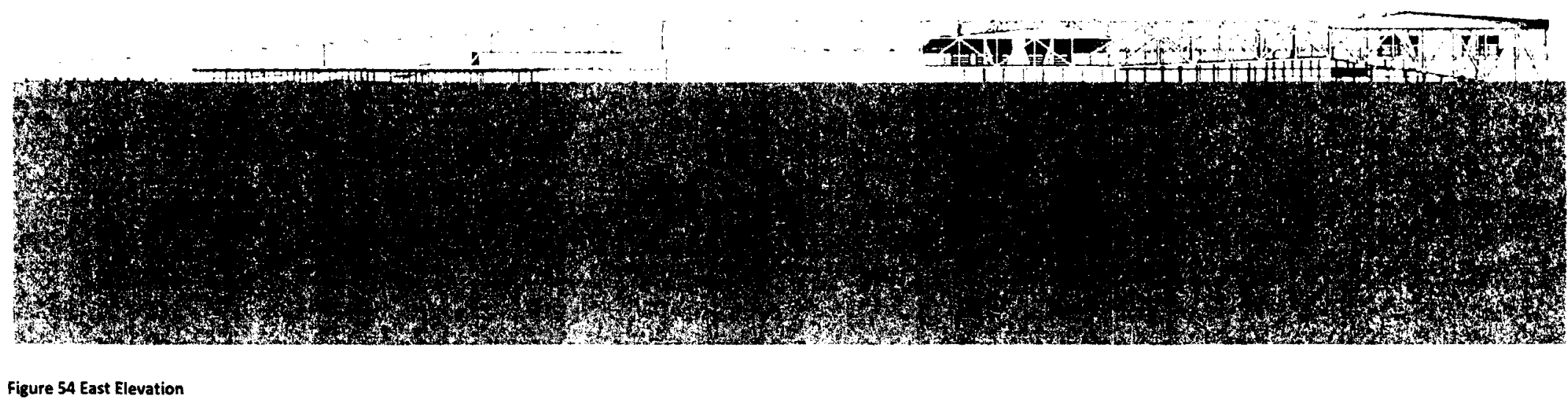




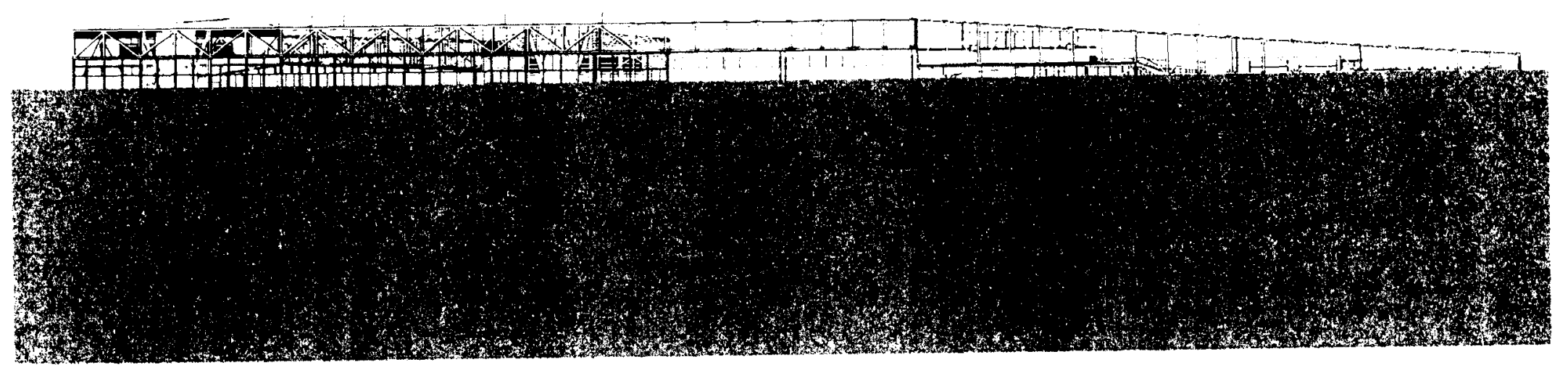

Figure 55 West Elevation 


\subsection{Conclusion}

rainspotting 2012: Travel, Leisure, and Everyday Life in Hong Kong merely illustrates one way of how multiple forces can be a determinant in the continual evolutionary process of the train station typology. The historical development of the railway station revealed that the form of train stations in the past was determined by functional needs. As the train station typology become more refined during the 1850 s, its shape and form proliferated among the rest of the world as a generic solution to the common conditions associated with railway stations. The railway stations of today, however, due to both their extensive size and their proximity to urban centers, possess an extended role as an urban activity generator. In the case of the XRL Terminus in Kowloon West, the multiple contexts of transitional culture and intricate multilayered infrastructural networks evolved the intermodal hub into an integrated urban node.

In the global picture, the problems of population density, busy circulation networks and lack of public spaces are shared by many cities in the world, but what continually makes these centers so appealing, however, is that their very density allows for more effective public transportation systems, pedestrian journeys throughout the urban core and the benefits of adjacent programmatic activities within the urban fabric; all of which lead to significant savings in time and energy use. It is, therefore, imperative for architects and urban planners to treat large scale, integrated urban development such as train terminals as more than merely circulatory infrastructure. That is not to say the importance of the design of transit-related structures should be diminished in anyway, but rather, they should be leveraged as a foundation on which to implement programs that cater to the surrounding urban environment. In other words, Marc Augé's concept of 'non-places' which are often associated with infrastructural developments, possess the inherent potential to become 'places': "non-places are not necessarily all 
encompassing; places, which are encrusted with creative social life, still exists and in some cases,

tend to reconstitute itself inside it." ${ }^{39}$

${ }^{39}$ Augé, Marc. Non-places: Introduction to an Anthropology of Supermodernity. London: Verso, 1995. Print. p87 


\section{References}

- Augé, Marc. Non-places: Introduction to an Anthropology of Supermodernity. London: Verso, 1995. Print.

- Abbas, M. A. Hong Kong: Culture and the Politics of Disappearance. Minneapolis: University of Minnesota, 1997. Print.

- Binney, Marcus. Architecture of Rail: The Way Ahead. London: Academy Editions, 1995. Print.

- Chan, Ming K., and Alvin Y. So. Crisis and Transformation in China's Hong Kong. Armonk, NY: M.E. Sharpe, 2002. Print.

- Chiu, Stephen Wing-kai., and Dale Lü. Hong Kong Becoming a Chinese Global City. London: Routledge, 2009. Print.

- Davis, Sydney G. Hong Kong in Its Geographical Setting. London: Collins, 1976. Print.

- Finizio, Gino. Architecture \& Mobility: Tradition and Innovation. Milano: Skira, 2006. Print

- Frampton, Kenneth. Modern Architecture: A Critical History. New York: Oxford UP, 1980. Print.

- Friedman, Thomas L. The World is Flat: a Brief History of the Twenty-first Century. New York: Farrar, Straus and Giroux, 2005. Print.

- Graf, Arndt, and Beng Huat. Chua, eds. Port Cities in Asia and Europe. London: Routledge, 2009. Print.

- Graham, Stephen, and Simon Marvin, eds. Splintering Urbanism: Networked Infrastructures, Technological Mobilities and the Urban Condition. New York: Routledge, 2001. Print.

- Gutierrez, Laurent, Ezio Manzini, and Valérie Portefaix, eds. HK Lab. Hong Kong: Map Book, 2002. Print.

- Koolhaas, Rem. Delirious New York: a Retroactive Manifesto for Manhattan. New York: Oxford UP, 1978. Print.

- Meeks, Carroll L. V. The Railroad Station. An Architectural History. New Haven: Yale U. P., 1956. Print.

- Mitchell, Alexander D. Train Stations: Whistle Stops, Rail Stations, and Train Depots of North America. Philadelphia: Courage, 2002. Print.

- Muller, Gerhardt, and John H. Mahoney. Intermodal Freight Transportation. Westport, Conn. (P.O. Box 2055, Westport 06880): Eno Foundation for Transportation, 1989. Print.

- Powell, Ken.Grand Central Terminal: Warren and Wetmore. London: Phaidon, 1996.

- Ross, Julian. Railway Stations: Planning, Design, and Management. Oxford: Architectural, 2000. Print.

- Shelton, Barrie, Justyna Karakiewicz, and Thomas Kvan. The Making of Hong Kong: from Vertical to Volumetric. New York, NY: Routledge, 2011. Print.

- Siu, Helen F., and Agnes S. Ku, eds. Hong Kong Mobile: Making a Global Population. Hong Kong: Hong Kong UP, 0920. Print.

- Solomon, Jonathan, Clara Wong, and Adam Frampton. Cities Without Ground: A Hong Kong Guidebook. ORO Editions, 2012. Print.

- Stoll, Katrina, and Scott Lloyd. Infrastructure as Architecture Designing Composite Networks. Berlin: Jovis, 2010. Print.

- Tsang, Steve Yui-Sang. A Modern History of Hong Kong. London: I.B. Tauris, 2004. Print.

- Wolf, Peter. The Future of the City: New Directions in Urban Planning. New York: Watson-Gultill Publications, 1974. Print. 
- "The Inception of the English Railway Station". Architectural History(SAHGB Publications Limited)

- Kandee, Somrudee. "Intermodal Concept in Railway Station Design". 〈http://www.bu.ac.th/knowledgecenter/epaper/jan_june2004/somruedee.pdf>

- DeWolf, Christopher DeWolf (2011, July $6^{\text {th }}$ ). China Daily Edition, HK Focus

- Henry, Lyndon, and Marsh, David. "Intermodal Surface Public Transport Hubs: Harnessing Synergy for Success in America's Urban and Intercity Travel". 2008. < http://www.vtpi.org/henry_marsh.pdf>

- Government of Hong Kong, "Hong Kong Section of Guangzhou-Shenzen-Hong Kong Express Rail Link Project Profile". April 2008. <http://www.epd.gov.hk/eia/register/profile/latest/esb189/esb189.pdf>

- "West Kowloon Terminus of the Guangzhou-Shenzhen-Hong Kong Express Rail Link-Briefing by Railway Developed Office, Highway development office, Highways deparapment." Nard of the Wet Kowloon Cultural District Authority. 26 November 2009.

- "Population Density by Area". Census and Statistics Department, Hong Kong Government. 2009.

- "Population estimate of Macao (2nd Quarter/2010) ('000)". Statistics and Census Service. Macao SAR Government, 2010

- "Ranking of districts of Maharashtra by population size 2011". CensusIndia.gov.in, 2011

- "Population and dwelling counts, for Canada and census subdivisions (municipalities), 2011 